\title{
Experimental Validation of Frequency-Domain Finite-Difference Model of Active Pipe-embedded Building Envelope in Time Domain by Using Fourier Series Analysis
}

\author{
Junlong Xie ${ }^{\mathrm{a}}$, Xinhua $\mathrm{Xu}^{\mathrm{b}}$, Anbang $\mathrm{Li}^{\mathrm{b}}{ }^{\text {, }}$, Qiuyuan $\mathrm{Zhu}^{\mathrm{c}}$ \\ ${ }^{a}$ Department of Refrigeration \& Cryogenic Engineering, Huazhong University of Science \\ \& Technology, Wuhan, China \\ ${ }^{\mathrm{b}}$ Department of Building Environment \& Energy Engineering, Huazhong University of \\ Science \& Technology, Wuhan, China \\ ${ }^{\mathrm{c}}$ Wuhan $2^{\text {nd }}$ Ship Design and Research Institute, Wuhan, China
}

\begin{abstract}
Active pipe-embedded building envelope is a new kind of external building wall or roof which usually has pipes embedded in it to let water circulate in these pipes for heat transfer. This structure may effectively intercept the heat/coolth from the ambient environment to indoor space and provide extra space conditioning for the indoor space. Frequency-Domain Finite-Difference (FDFD) model can predict the frequency thermal response of active pipe-embedded building envelope directly and provide some important guidelines for system control and system sizing. This paper presents the experimental validation of this model in time domain by using Fourier series analysis. An experiment test rig was developed for the thermal response measurements of the pipe-embedded
\end{abstract}


building envelope under pre-defined conditions. Firstly, the measured time series of surface temperatures are transformed into complex Fourier series by using Discrete Fourier Transform and applied into the FDFD model as the boundary condition for calculation. Then, the calculated frequency thermal responses by FDFD model can be easily transformed into time series by using Inverse Discrete Fourier Transform. Finally, the time-domain thermal responses of FDFD model are obtained. The results show that the calculated time-domain thermal responses of the active pipe-embedded building envelope by using FDFD model agree well with the experimental measurements.

Keyword: Active pipe-embedded building envelope, FDFD model, Frequency thermal response, Fourier series analysis, Discrete Fourier Transform

* Corresponding author: Anbang Li, LiAnbang@hust.edu.cn Tel.: +86 27-87792165 ext 403; fax: +86 27-87792101 


\section{Nomenclature}

c $\quad$ specific heat $\left(\mathrm{J} /\left(\mathrm{m}^{2} \cdot \mathrm{K}\right)\right)$

$\lambda \quad$ thermal conductivity $(\mathrm{W} / \mathrm{m} \cdot \mathrm{K})$

$\rho \quad$ density $\left(\mathrm{kg} / \mathrm{m}^{3}\right)$

$\theta \quad$ temperature $(\mathrm{K})$

$A \quad$ amplitude of the harmonic temperature variation (K)

$S_{p} \quad$ spacing between adjacent pipes ( $\mathrm{mm}$ )

$\delta \quad$ thickness of the pipe-embedded building envelope ( $\mathrm{mm})$

$N_{c} \quad$ the total number of the cells of FDFD model

$s \quad$ heat transfer coefficient between two contiguous nodes $(\mathrm{W} / \mathrm{m} \cdot \mathrm{K})$

$x \quad$ space coordinate $(\mathrm{m})$

$y \quad$ space coordinate $(\mathrm{m})$

$d x \quad y$-direction increment $(\mathrm{m})$

$d y \quad x$-direction increment (m)

$i \quad$ symbol of $\sqrt{-1}$

$\omega \quad$ angular frequency $(\mathrm{rad} / \mathrm{s})$

$\varphi \quad$ phase angle $(\mathrm{rad} / \mathrm{s})$

$u \quad$ real part of the complex quantity

$v \quad$ image part of the complex quantity

$d_{n} \quad$ discrete Fourier series of periodic time series

$f(t) \quad$ periodic continuous-time signal

$t \quad$ time (s)

$\Delta t \quad$ sampling interval (h)

$N \quad$ total number of the discrete values in a time series

$h \quad$ number of harmonics

$S_{h} \quad$ total energy of $h$ harmonics

$\zeta_{h} \quad$ percentage proportion of $S_{h}$ and $S_{N / 2}$

$P_{k} \quad$ time-domain thermal responses at the $k$ - $t h$ time step

$\bar{P} \quad$ steady-state time-domain thermal responses

$\tilde{P}_{(n, k)} \quad$ dynamic time-domain thermal responses the $n$-th harmonic at the $k$-th time step $\theta_{j}^{\prime}(k \cdot \Delta t)$ time-domain temperature response of cell $j$ at $k$-th time step $(\mathrm{K})$ 
$\bar{\theta}_{i}^{\prime} \quad$ time-domain steady-state temperature response of cell $j(\mathrm{~K})$

$\tilde{\theta}^{(n, k \cdot k \tau)}$ dynamic time-domain temperature response (i.e. temperature responses to the harmonic with $\omega>0$ ) of cell $j$ to the $n$-th harmonic at the $k$-th time step (K)

$u_{(n, j)}^{\prime} \quad$ the real part of the frequency temperature responses of cell $j$ to the $n$-th harmonic calculated by FDFD model

$v_{(n, j)}^{\prime} \quad$ the imaginary part of the frequency temperature responses of cell $j$ to the $n$-th harmonic calculated by FDFD model

DFT Discrete Fourier Transform

IDFT Inverse Discrete Fourier Transform

FDFD Frequency-Domain Finite-Difference

\section{Symbols}

$\sim \quad$ dynamic response

- $\quad$ steady/average response

$\wedge \quad$ conjugate complex number

the thermal responses calculated by FDFD model

\section{Introduction}

Active pipe-embedded building envelope (i.e. wall or roof) is a new kind of building envelope which has pipe embedded inside and lets the circulating cool water or hot water pass through it to temper the building envelope. It not only can intercept the heat/coolth exchange between the ambient environment and the indoor space to reduce building cooling/heating load but also provide extra space conditioning for the room [Xu et al. 2010]. The circulating water in the pipe-embedded building envelope functions as a heat sink or heat source to discharge or charge the pipe-embedded building envelope actively, distinguished from passive application forms (eg. a high-mass solid building envelope [Wang et al. 2014, Favre and Peuportier 2014]). Passive applications utilize the thermal storage of building mass to shift or reduce the peak cooling or heating load in the forms of passive heat exchange. Just like the other pipe-embedded structures such as pipe-embedded floor or ceiling etc., the pipe-embedded building envelope has some similar advantages over the traditional air-conditioning system such as more stable and comfortable inner environment, no drought sensation, utilization of relatively low (high) 
temperature water produced by renewable energy [Lehmann et al. 2007, Saelens et al. 2011, Liu et al. 2011, Dréau and Heiselberg 2014]. The purpose of the research project about the active pipe-embedded building envelope is to investigate the insulation effect and the space cooling capacity of this structure as well as the feasibility of integrating this structure with the low-grade or renewable energy resources. For this purpose, both the efficient and accurate heat transfer model of this structure and relevant experiments are necessary.

Since the transient heat transfer of this structure with high thermal inertia is complicated especially with heat/coolth storage process, accurate heat transfer model of this structure is important for system size and optimal system operation. There are large amount of researches aimed at the heat transfer model of the pipe-embedded structure such as pipe-embedded floor or ceiling while the heat transfer model of the pipe-embedded building envelope is rarely mentioned.

Analytical solution is one of the most chosen ones for the heat transfer problem. Different from panel structure, the geometrical shape of the pipe-embedded structures (i.e. pipe-embedded floor or ceiling) are irregular, and the heat transfer problem of this structure is difficult to solve analytically and a large degree of model simplification must be made for analytical solution [Zhang and Pate 1987, Antonopoulos 1992, Chen et al. 2013, Tian et al. 2014]. Numerical method such as Finite Difference Method (FDM), Finite Element Method (FEM), Finite Volume Method (FVM) etc. can provide accurate solutions for the heat transfer problem of the pipe-embedded structure as long as the meshing is sufficiently denser. Many researchers [Zhang and Pate 1986, Ho et al. 1995, Antonopoulos 1997, Jin et al. 2010, Carli et al., 2012, Wang et al. 2014] developed detailed numerical models for the pipe-embedded radiant ceiling panel or hydronic heating floor, and some experiments were carried out to validate the numerical model. These numerical models are calculated in time domain. The computation cost is heavy, and the calculating process is also time-consuming especially for obtaining the quasi-steady-state solution of the periodic heat transfer problem because the repetitive iteration process for stabilization is required

Pipe-embedded floor or ceiling is generally imposed by two thermal disturbances i.e. circulating water in pipes and indoor environment. However, active pipe-embedded building envelope (i.e. wall or roof) is imposed by the violently changed ambient 
environment except circulating water in pipes and indoor environment. The heat transfer problem of active pipe-embedded building envelope becomes more complicated than that of the pipe-embedded ceiling/floor. The ambient environment including outdoor air temperature, solar radiation etc. change rapidly in a day. The fore-mentioned steady-state analytical solution of pipe-embedded structures such as pipe-embedded floor or ceiling is not applicable to the pipe-embedded building envelope. In fact, the analytical solution is very difficult to obtain. The numerical model in time domain is also time-consuming.

Frequency-domain Finite Difference (FDFD) method [Chabory et al. 2008, Melazzi et al. 2012], a numerical method in frequency domain, has been widely used in the electromagnetic fields and shown its clear advantage over the time-domain numerical method in solving the periodic problem in this field or calculating the frequency characteristics of the magnetic field. Xie et al. [2012] developed a FDFD model of

pipe-embedded building envelope and calculated the frequency thermal characteristics of this structure by using this FDFD model. This FDFD model can give a fast and direct solution of the dynamic thermal characteristics of the pipe-embedded building envelope, and a thorough frequency thermal analysis of this structure can be easily achieved. Zhu et al. [2014] used the FDFD model to calculate the theoretical frequency thermal characteristics of this structure as reference to develop an equivalent simplified RC-network model.

This paper presents the experimental validation of the FDFD model of the pipe-embedded building envelope in time domain since all the measurements are discrete time series and the validation in time domain is intuitional. An experiment test rig is developed for the measurements of the thermal responses of the pipe-embedded building envelope under pre-defined dynamic conditions. Since the required boundary conditions and the calculated results of the FDFD model are all in frequency-domain, Fourier series analysis methods including Discrete Fourier Transform (DFT) and Inverse Discrete Fourier Transform (IDFT) [Kreyszig 2011] are used to realize the transformation of boundary conditions and calculated results between time-domain and frequency-domain results. The results show the FDFD model can predict the thermal performance with good accuracy, and is effective for thermal performance analysis.

\section{Description of the frequency-domain finite-difference model}


This model has been presented in Refs [Xie et al. 2012, Zhu et al. 2014]. It is duplicated here for coherence. Figure 1 shows the typical cross section of the active pipe-embedded building envelope. Figure 2 shows the typical operations of the active pipe-embedded building envelope. In cooling condition, the internal and external surface temperatures of this structure are lower than the corresponding indoor and outdoor environment temperature respectively. The water pipe with slightly cooler water (e.g. 19 ${ }^{\circ} \mathrm{C}$ ) circulating inside it will act as a heat sink. The heat transfer from the outdoor environment is intercepted, and it may also absorb heat from indoor air. In heating condition, the internal and external surface temperatures of this structure are higher than the corresponding indoor and outdoor environment temperatures respectively. The water pipe with slightly hot water (e.g. $25^{\circ} \mathrm{C}$ ) circulating inside it will act as a heat source. The water releases heat for preventing the heat loss of indoor air. The slightly cooler or hot water may be easily available from the low-grade energy resources, i.e. cooling tower, ground heat exchanger etc.

$<$ Figure 1 Schematic of the cross section of the active pipe-embedded building envelope $>$

$<$ Figure 2 Typical operations of the active pipe-embedded building envelope, (a) cooling condition, (b) heating condition>

The pipe can be positioned in any position. In this study, only the case that the pipe is positioned in the middle of the mortar layer is investigated for description. The active pipe-embedded building envelope may have different pipe spacing such as $100 \mathrm{~mm}$, $150 \mathrm{~mm}, 200 \mathrm{~mm}, 250 \mathrm{~mm}$ and $300 \mathrm{~mm}$ etc. In this study, the pipe spacing is taken as $200 \mathrm{~mm}$. To simplify the heat transfer model of this structure, the heat transfer along the length direction of the pipe is neglected, and the heat transfer model can be simplified as a two-dimensional one.

The heat transfer along and within the water loop is not considered and only the solid part of this structure is considered in the modeling process of the pipe-embedded building envelope. The water flow in the pipe is considered as a boundary condition similar to the ambient environment or the indoor environment. Therefore, the two-dimensional transient heat conduction partial differential equation within the solid part of this structure may be described as Equation (1). Any temperature variation can be decomposed into a series of finite harmonic (i.e. sinusoidal or cosinusoidal) temperatures with different 
frequencies and phase differences. A harmonic temperature wave can be expressed in complex form as Equation (2) [Weber 2004]. This harmonic temperature includes a real part and an imaginary part. Based on the equilibrium of the real part on the left side and the real part on the right side as well as the equilibrium of the imaginary part on the left side and the imaginary part on the right side, Equation (5) and (6) are subsequently obtained which don't include imaginary value $i$ (i.e. $\sqrt{-1}$ ). Therefore, the imaginary value with $i$ (i.e. $\sqrt{-1}$ ) doesn't have any effect on the calculation process. Equation (1) can be

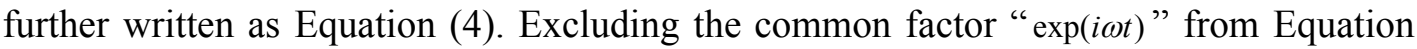
(4), the equation can be represented as two elliptic partial differential equations, Equation (5) and (6). They are for the real part and imaginary part of $\theta$ respectively. Thus, the solution of the transient heat conduction problem of the pipe-embedded building envelope is equivalent to solving the two elliptic partial differential equations, Equation (5) and (6).

$$
\begin{gathered}
\rho c \frac{\partial \theta}{\partial t}=\frac{\partial \theta}{\partial x}\left(\lambda \frac{\partial \theta}{\partial x}\right)+\frac{\partial \theta}{\partial y}\left(\lambda \frac{\partial \theta}{\partial y}\right) \\
\theta=A \exp (i(\omega t+\varphi))=(u+i v) \exp (i \omega t) \\
u=A \sin \varphi, \quad v=A \cos \varphi \\
i \omega \rho c \theta=\frac{\partial \theta}{\partial x}\left(\lambda \frac{\partial \theta}{\partial x}\right)+\frac{\partial \theta}{\partial y}\left(\lambda \frac{\partial \theta}{\partial y}\right) \\
-\omega \rho c v=\frac{\partial u}{\partial x}\left(\lambda \frac{\partial u}{\partial x}\right)+\frac{\partial u}{\partial y}\left(\lambda \frac{\partial u}{\partial y}\right) \\
\omega \rho c u=\frac{\partial v}{\partial x}\left(\lambda \frac{\partial v}{\partial x}\right)+\frac{\partial v}{\partial y}\left(\lambda \frac{\partial v}{\partial y}\right)
\end{gathered}
$$

Where $\theta$ is the temperature, $\mathrm{K} ; x, y$ are the space coordinates, $\mathrm{m} ; t$ is time, $\mathrm{s} ; \rho, \mathrm{c}, \lambda$ are the density $\left(\mathrm{kg} / \mathrm{m}^{3}\right)$, specific heat $(\mathrm{J} / \mathrm{kg} \cdot \mathrm{K})$ and thermal conductivity $(\mathrm{W} / \mathrm{m} \cdot \mathrm{K}) . A$ is the amplitude of the harmonic temperature variation $\theta, \mathrm{K} ; i$ is the symbol of $\sqrt{-1} ; \omega$ is the angular frequency, $\mathrm{rad} / \mathrm{s} ; \varphi$ is the phase angle, $\mathrm{rad} ; u$ and $v$ are the real part and image part of the complex quantity respectively.

The unit section abcd (i.e. $0 \leq x \leq \delta, 0 \leq y \leq S_{p}$ ) of this pipe-embedded building envelope is used for model development. Basing on the assumption that the water temperature variation along the pipe is neglected, the faces (i.e., the upper surface $a b$ and 
the lower surface $c d$ of cross section $a b c d$ ) between two adjacent embedded pipes are regarded as adiabatic. The left surface $a c$ and right face $b d$ of cross section $a b c d$ are the external wall surface and internal wall surface respectively. The heat transfer of the active pipe-embedded building envelope is assumed a linear and time-invariant problem (i.e. all the thermal physical coefficients are constant and independent of the temperature and the time).

Classical finite-difference principle is used for discretizing the typical section abcd into $N_{c}$ cells as shown in Figure 3. Each cell in this model is represented by using four resistances and one capacitance, and the temperature of the capacitance represents the temperature of the cell. Equation (7) and (8) describe the center-difference forms of the partial differential (5) and (6) for cell 0 respectively as shown in Figure 3. Combining Equation (7) and (8), a $2 \times 2$ matrix equation (i.e. Equation (9)) can be obtained. Accordingly, the total $\left(2 N_{c}\right) \times\left(2 N_{c}\right)$ matrix equation (Equation (10)) of $N_{c}$ cells can be obtained afterwards to present the FDFD model of the active pipe-embedded building envelope. Generalized minimal residual method (GMRES) [Saad and Schultz 1986] is one of the most used iterative methods for solving the large sparse linear equations, and it is used for solving Equation (10).

$<$ Figure 3 Discrete grid model of the active-embedded building envelope $>$

$$
\begin{aligned}
& s_{1}\left(u_{1}-u_{0}\right)+s_{2}\left(u_{0}-u_{0}\right)+s_{0}\left(u_{0}-u_{0}\right)+s_{4}\left(u_{4}-u_{0}\right)=-d x d y \rho c v_{0} \\
& s_{1}\left(v_{1}-v_{0}\right)+s_{2}\left(v_{0}-v_{0}\right)+s_{0}\left(v_{0}-v_{0}\right)+s_{4}\left(v_{4}-v_{0}\right)=d x d y \rho c u_{0} \\
& {\left[\begin{array}{cc}
s_{1}+s_{2}+s_{3}+s_{4} & -d x d y \rho c \omega \\
d x d y \rho c \omega & s_{1}+s_{2}+s_{3}+s_{4}
\end{array}\right]\left[\begin{array}{l}
u_{0} \\
v_{0}
\end{array}\right]=\left[\begin{array}{l}
s_{1} u_{1}+s_{2} u_{2}+s_{3} u_{3}+s_{4} u_{4} \\
s_{1} v_{1}+s_{2} v_{2}+s_{3} v_{3}+s_{4} v_{4}
\end{array}\right]}
\end{aligned}
$$




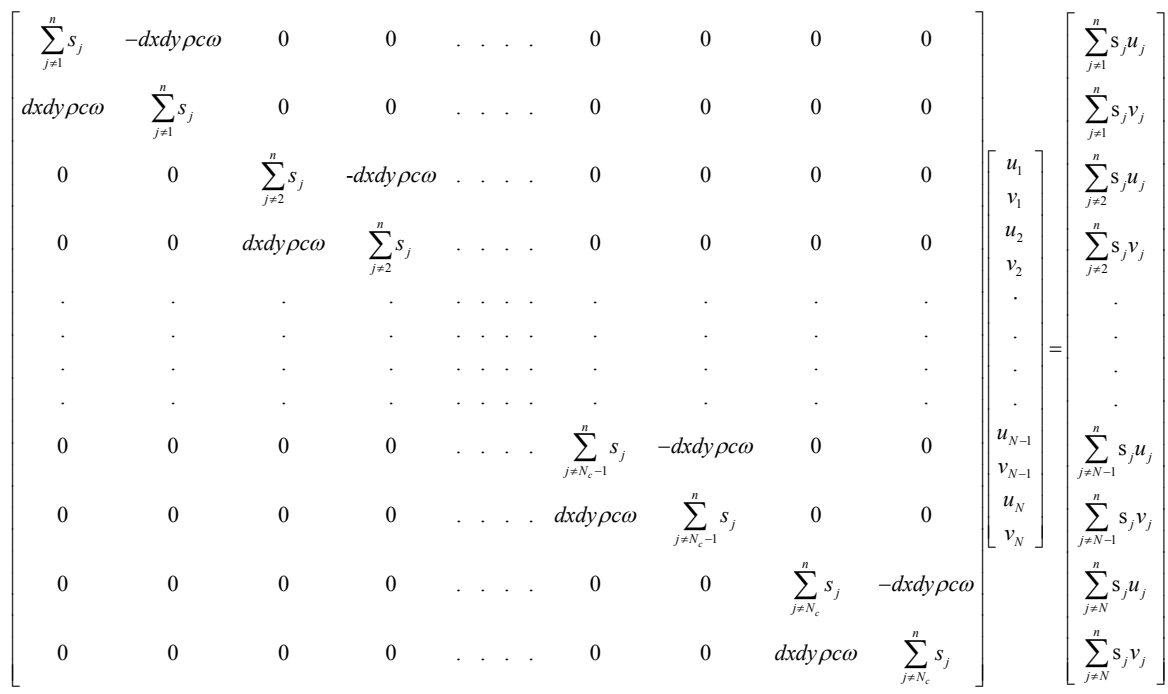

$$
\begin{aligned}
& \mathrm{s}_{j}=\frac{d y_{0}}{\frac{d x_{j}}{2 \lambda_{j}}+\frac{d x_{0}}{2 \lambda_{0}}}(j=1,2), \quad \mathrm{s}_{j}=\frac{d x_{0}}{\frac{d y_{j}}{2 \lambda_{j}}+\frac{d y_{0}}{2 \lambda_{0}}}(j=3,4)
\end{aligned}
$$

Where $s$ is the heat transfer coefficient between two adjacent nodes, $\mathrm{W} / \mathrm{m} \cdot \mathrm{K} ; d x$ and $d y$ are the $y$-direction increment and $x$-direction increment, $\mathrm{m} ; N_{c}$ is the total number of cells; subscripts $j$ is the number of the cells or boundary nodes.

\section{Fourier series analysis}

\subsection{Expansion of Fourier series of periodic discrete signals}

Suppose a periodic continuous-time signal $f(t)$ with a period $T$. A periodic time series $[f(k T / N)]$ can be obtained as Equation (12) when subdividing $[0, T]$ into $N$ equal parts of length $T / N$.

$$
\left[f\left(k \cdot \frac{T}{N}\right)\right]=\left[f\left(1 \cdot \frac{T}{N}\right), f\left(2 \cdot \frac{T}{N}\right), \cdots, f\left(N \cdot \frac{T}{N}\right)\right]
$$

Discrete Fourier Transform (i.e., DFT) of the periodic time series $[f(k T / N)]$ is described as Equation(13). Conversely, the periodic time series $[f(k T / N)]$ can also be obtained by using Inverse Discrete Fourier Transform (i.e., IDFT) when DFT series of periodic time series are given. The approximation of the IDFT series is shown as Equation (14). The Nyquist-Shannon sampling theorem [Kreyszig 2011] requires that the number of the harmonics in the Fourier series approximation must be less than half of the sampling frequency $N$. Thus, Equation (14) can be expressed further as Equation (15).

$$
d_{n}=\sum_{k=0}^{N-1} f\left(k \frac{T}{N}\right) e^{-i n k \cdot \frac{2 \pi}{N}}=u_{n}+i v_{n}, n=0,1,2, \cdots, N-1
$$




$$
\begin{aligned}
& f\left(k \cdot \frac{T}{N}\right) \approx \frac{1}{N} \sum_{n=0}^{N-1}\left(d_{n} e^{i n k \cdot \frac{2 \pi}{N}}+\hat{d}_{n} e^{-i n k \cdot \frac{2 \pi}{N}}\right), k=0,1,2, \cdots, N-1 \\
& f\left(k \cdot \frac{T}{N}\right)=\frac{d_{0}}{N}+\frac{1}{N} \sum_{n=1}^{h}\left[d_{n} e^{i n k \cdot \frac{2 \pi}{N}}+\hat{d}_{n} e^{-i n k \cdot \frac{2 \pi}{N}}\right], k=0,1,2, \cdots, N-1, h \leq N / 2
\end{aligned}
$$

From the above derivation, the Fourier series approximation of a measured periodic time series of temperature $\theta(k \cdot \Delta t)$ with the sampling interval of $\Delta t$ and sampling frequency $N$ is expressed as Equation (16) and Equation (17).

$$
\begin{aligned}
\theta(k \cdot \Delta t) & =\frac{1}{N} \sum_{n=0}^{h}\left[\left(u_{n}+i v_{n}\right) \mathrm{e}^{i n k \cdot \frac{2 \pi}{N}}+\left(u_{n}-i v_{n}\right) \mathrm{e}^{-i n k \cdot \frac{2 \pi}{N}}\right], k=0,1,2, \cdots, N-1, h \leq N / 2 \\
u_{n}+i v_{n} & =\sum_{k=0}^{N-1} \theta(k \cdot \Delta t) e^{-i n k \cdot \frac{2 \pi}{N}}, n=0,1,2, \cdots, h
\end{aligned}
$$

\subsection{Analysis of the order and energy density}

Based on the Nyquist-Shannon sampling theorem, the Fourier series approximation for a periodic time series with $N$ discrete values may be composed of $N / 2$ harmonics (i.e., the order) at most. For example an hourly sampling sequence with the period of $24 h$ means the maximum of 12 harmonics is allowed. Higher order (i.e., more harmonics) may increase the accuracy of the Fourier series approximation. However, the calculation efficiency may be decreased. Proper order is a good compromise between accuracy and calculation efficiency. Therefore, how to determine the proper order within the requirement of the Nyquist-Shannon sampling theorem is worth analyzing.

$\left|d_{n}\right|^{2}$ represents the contribution of the harmonic with the frequency of $2 \pi n / N$ to the total energy of the signal and is called the power density of the signal [Oppenheim et al. 1996]. The total energy $S_{h}$ of $h$ harmonics (i.e., $h$ order) can be calculated by using Equation (18). The percentage proportion of $S_{h}$ and $S_{N / 2}$ is expressed by Equation (19). Usually, the number of harmonics (i.e., the order) is not sufficient until the proportion $\zeta n$ reaches a specified threshold value (say 99\%). Then, the Fourier series approximation is considered to describe the original sampling data accurately enough.

$$
\begin{aligned}
& S_{h}=\sum_{n=0}^{h}\left|d_{n}\right|^{2}, h \leq N / 2 \\
& \zeta_{h}=\frac{S_{h}}{S_{N / 2}} \times 100 \%, h \leq N / 2
\end{aligned}
$$




\section{Thermal response of FDFD model in time domain}

The thermal system of the active pipe-embedded building envelope is a typical linear and time-invariant system since all the thermal physical coefficients are constant. Based on the superposition principle of linear and time-invariant system, the time-domain thermal responses of the pipe-embedded building envelope can be expressed as the sum of the individual time-domain thermal responses under the excitation of the harmonics of different frequencies as Equation (20). The frequency thermal response at a frequency point (i.e., $\omega$ ) denoted by $u$ and $v$ can be calculated by using the FDFD model. This frequency thermal response is used to calculate the time-domain thermal response as Equation (21). In this equation, only the temperature is concerned. The surface heat flux of the pipe-embedded building envelope in time domain can also be easily obtained with the given temperature. The process of solving the thermal responses of FDFD model in time-domain is described as Figure 4.

$$
\begin{gathered}
P_{k}=\bar{P}+\sum_{n=1}^{h} \tilde{P}_{(n, k)}, k=0,2, \cdots, N-1 \\
\theta_{j}^{\prime}(k \cdot \Delta \tau)=\bar{\theta}_{j}^{\prime}+\sum_{n=1}^{h} \tilde{\theta}_{j}^{\prime(n, k \Delta \tau)}=\bar{\theta}_{j}^{\prime}+\sum_{n=1}^{h}\left[\left(u_{(n, j)}^{\prime}+i v_{(n, j)}^{\prime}\right) \mathrm{e}^{i n k \cdot \frac{2 \pi}{N}}+\left(u_{(n, j)}^{\prime}-i v_{(n, j)}^{\prime}\right) \mathrm{e}^{\left.-i n k \cdot \frac{2 \pi}{N}\right], k=01,2, \cdots, N-1}\right.
\end{gathered}
$$

Where, $P_{k}$ represents the time-domain thermal responses at the $k$-th time step (The thermal response can be temperature or heat flux); $\bar{P}$ represents the steady-state time-domain thermal responses (i.e. thermal responses with $\omega=0) ; \tilde{p}_{(n, k)}$ represents the dynamic time-domain thermal responses to the $n$-th harmonic at the $k$-th time step; $\theta_{j}^{\prime}(k \cdot \Delta \tau)$ represents the time-domain temperature of cell $j$ at $k$-th time step, $\bar{\theta}_{j}^{\prime}$ represents the steady time-domain temperature response of cell $j$ with $\omega=0, \tilde{\theta}_{j}^{(n, k \Delta \tau)}$ represents the dynamic time-domain temperature responses of cell $j$ to the $n$-th harmonic at the $k$-th time step; $u_{(n, j)}^{\prime}$ and $v_{(n, j)}^{\prime}$ represents the real part and imaginary part respectively of the frequency temperature responses of cell $j$ to the $n$-th harmonic calculated by the FDFD model.

$<$ Figure 4 The process of solving the time-domain thermal responses of FDFD model $>$

\section{Description of the test facility}

\subsection{Test rig arrangement}


An experiment test rig was built for measuring the thermal responses of the pipe-embedded building envelope for validating the FDFD model. The experiment schematic diagram is shown in Figure 5. The test room with the net dimension of $5600 \mathrm{~mm}$ (length) $\times 3300 \mathrm{~mm}$ (width) $\times 2800 \mathrm{~mm}$ (height) is separated by the test sample of the pipe-embedded envelope into two chambers. One chamber is $3350 \mathrm{~mm}$ (length) $\times$ $3330 \mathrm{~mm}$ (width) $\times 2800 \mathrm{~mm}$ (height) and used for simulating the outdoor ambient environment. The other chamber is $2250 \mathrm{~mm}$ (length) $\times 3300 \mathrm{~mm}$ (width) $\times 2800 \mathrm{~mm}$ (height) and used for simulating the indoor environment. The test room is located in a laboratory room with stable environment. The surrounding walls, roof and floor of the test room were constructed by $125 \mathrm{~mm}$ insulation plate. The test sample of the pipe-embedded building envelope is $3300 \mathrm{~mm}$ (length) $\times 310 \mathrm{~mm}$ (thickness $) \times 2400 \mathrm{~mm}$ (height). The cool water circulating in the embedded pipe is supplied by a water system mainly comprised of a chiller and a thermal insulation water tank. Electric heaters are used for heating to simulate the indoor and outdoor thermal disturbances, and the air temperatures in both two chambers are respectively controlled by a PID controller. All the measurements are collected by a data acquisition unit and recorded in a PC.

\section{$<$ Figure 5 Schematic diagram of the experiment test rig $>$}

\subsection{The construction of the test sample}

The test sample of pipe-embedded building envelope consists of three layers which are two $120 \mathrm{~mm}$ thickness brick layers and one $40 \mathrm{~mm}$ thickness pipe-embedded mortar layer. Due to the present of pipes in the mortar layer, the construction process of the sample is more complicated than the conventional wall. Figure 6 shows the construction process. Firstly, a $120 \mathrm{~mm}$ thickness brick wall with $15 \mathrm{~mm}$ thickness mortar layer on both surfaces was constructed as shown in Figure 6(a). Secondly, polypropylene pipe with the diameter of $20 \mathrm{~mm}$ was arranged parallel and fixed on the internal surface with the spacing of $200 \mathrm{~mm}$ as shown in Figure 6(b). Finally, construction of the pipe-embedded layer is the most complicated yet the key step. It should proceed at the same time with the construction of the second brick wall of $120 \mathrm{~mm}$ thickness. During the construction process, the fresh mortar was poured instantly into the gap between the two brick walls, as shown in Figure 6(c). One thing worth paying attention is to make the gap fully filled with the fresh mortar and insure the full contact between the fresh mortar and pipe surface. The completed test sample of the pipe-embedded building wall is shown in 
Figure6(d). The thermal properties of the brick and mortar are listed in Table 1.

$<$ Figure 6 Construction process of the pipe-embedded building wall $>$

$<$ Table 1 Thermal properties of the brick and mortar in the test sample $>$

\subsection{Measurement and control}

15 thermal resistors were installed to measure the temperatures on each of the external surface and inner surface of the test sample of the pipe-embedded building envelope. They are distributed evenly on the surfaces of the test sample. Each thermal resistor is installed with $2 \mathrm{~mm}$ depth on both surfaces to represent the surface temperature. 6 heat flow meters were stuck to both surfaces by using vaseline to measure the surface heat flux.

The wall is relative thick (half of the thickness is $155 \mathrm{~mm}$ ), and the wall surface temperature is almost uniform and the water temperature along the pipe direction changes smoothly and gradually. The water temperature change along the pipe direction from the water inlet to the outlet is within $1.2^{\circ} \mathrm{C}$. Figure 7 is an example the temperature distribution on the cross section (just a unit section as shown in Figure 1) of the pipe-embedded building envelope obtained by using Program FLUENT. The temperature distributions both on the external surface and the internal surface of the unit section of the pipe-embedded building envelope are very uniform with the maximum difference within $0.1^{\circ} \mathrm{C}$. Therefore the heat flux and temperature distribution is basically uniform on the wall surfaces.

More heat flux meters are favorable for more point measurements for calculating the average value while the heat flow meter is expensive. The average of the measurements from the evenly distributed temperature sensors/heat-flow meters on the wall surface may give a reasonable and representative value for the actual one although the number of the thermal resistors and heat flow meters is limited.

$<$ Figure 7 The temperature distribution of the pipe-embedded building envelope. (a) two-dimensional temperature distribution on the cross section, (b) one-dimensional temperature distribution on the external surface and internal surface $>$

The air temperatures in two chambers are measured by thermal resisters at the height 
of $1.2 \mathrm{~m}$ and horizontal distance of $1.1 \mathrm{~m}$ from the test sample surface. To simulate the predefined inner air temperature profile and the outdoor solar-air temperature profile, electric heaters are installed in both test chambers to realize the air temperature rise. A PID controller is used to control the heating output of the electric heaters in each test chamber based on the track error between the measured air temperature and corresponding set-point as shown in Figure 8 (a).

The cool water circulating through the embedded pipe in the test sample is provided by a closed-loop water system which can keep the supply water temperature stable. The water system of the experiment rig is composed of two sub-loops: primary loop and secondary loop. In the primary loop, the cool water is produced by an air-cooled chiller with $2.5 \mathrm{~kW}$ cooling capacity (Figure 8 (b)), and then delivered to a thermal insulation water tank (Figure 8 (c)) through a primary pump. The thermal insulation water tank is used to keep the water temperature to the embedded pipe stable. The water flow in the secondary loop is metered by an electromagnetic flow meter and can be regulated by a regulating valve. Two temperature sensors are installed in the supply pipe and return pipe to measure the inlet and outlet temperatures of the test sample respectively.

All the thermal resistors and temperature sensors for temperature measurements are PT100 with the accuracy of $0.1^{\circ} \mathrm{C}$. The flow meter is with the accuracy of $0.3 \%$ from 0

$\mathrm{m}^{3} / \mathrm{h}$ to $5.7 \mathrm{~m}^{3} / \mathrm{h}$. The heat flux meter is with the accuracy of $5 \%$ and the conversion coefficient of $23.26 \mathrm{~W} / \mathrm{m}^{2} \cdot \mathrm{mV}$. All the measurements are collected every two minutes by a data acquisition unit produced by Agilent. A PC connected with this data acquisition unit is used for data monitoring, storing and processing.

\section{$<$ Figure 8 Some experimental devices $>$}

\subsection{Experiment cases}

The experiment was conducted under summer conditions. The setting (predefined) air temperature profile of the chamber for indoor environment is from a previous field-measurement of an air-conditioned commercial office building in Wuhan, China. The setting air temperature profile of the chamber for ambient environment is a typical hourly solar-air temperature at the south external wall in summer season. The temperature profiles are present in the following section. In this outdoor chamber, there is no 
simulated solar radiation to obtain the solar radiation on the wall. Usually, the dry-bulb temperature of the ambient air temperature is usually bellow $38^{\circ} \mathrm{C}$ or so. The heater is used the heat up the chamber air to so high (nearly $60^{\circ} \mathrm{C}$ ) to represent the solar-air temperature.

This experiment carried out three cases of different supply water temperatures (17.5 ${ }^{\circ} \mathrm{C}, 19^{\circ} \mathrm{C}$ and $20^{\circ} \mathrm{C}$ ) with the predefined air temperatures for the validation of the FDFD model. The effect of water flow rate on the heat transfer is not concerned since many studies [Zhang and Pate 1986, Antonopoulos 1992] have shown that the water flow temperature has far more significant influence on the heat transfer within the pipe-embedded structures such as floors, ceilings etc.. In the experiment, the water velocity of $0.5 \mathrm{~m} / \mathrm{s}$ was kept for all the cases to allow turbulent flow, and the water flow rate was constant, $0.48 \mathrm{~m}^{3} / \mathrm{h}$, during the experiments.

For any case, the setting indoor and outdoor solar-air temperature profiles were used periodically and repeatedly as set-point of the PID controllers to control the air temperature variation of the test chambers. The cool supply water with stable temperature and velocity was constantly delivered to the test sample until the semi-steady state reached. Generally, the experiment for one case was required to proceed for four or five days at least.

\section{Validation results}

\subsection{Boundary conditions and Fourier series analysis}

The above-mentioned experiment was conducted under predefined conditions and a large amount of experimental data was obtained. To keep identical boundary conditions between the experiment and the FDFD model, the measured actual boundary conditions are applied to the FDFD model as inputs to make calculations. The experimental results including the surface temperatures of the test sample, air temperatures in the chambers etc. show that the heat transfer process within the sample generally reach the semi-steady state after about three periods (i.e. three days) from the beginning of the experiment. Therefore the measured results in the last period are chosen as the periodic boundary condition of the FDFD model.

Figure 9 shows the comparison of the setting (predefined) and measured air temperature profiles in both chambers for the case with the supply water temperature of 
$19^{\circ} \mathrm{C}$. The measurements indicate that the PID control system can work well for both chambers to simulate the predefined conditions.

$<$ Figure 9 The predefined and measured air temperature profiles in both chambers $>$

The measured air temperatures in both chambers and heat transfer coefficients are applied into the FDFD model as the third boundary condition on the external surface and internal surface of the test sample. As for the heat transfer coefficient between the test sample surface and the ambient air, it is difficult to calculate exactly due to the complex coupling of convective heat transfer, conduction and radiation within the heat transfer process and nonlinear property. The heat transfer coefficient on each of the test sample surfaces is determined based on the measured heat flux of the test sample surface and the temperature difference between the measured air temperature and the measured surface temperature of the test sample for simplification. The third boundary condition on the internal pipe surface is also used for the FDFD model, i.e. water flow temperature and heat transfer coefficient between the water flow and internal pipe surface applied into FDFD model.

To realize the experimental validation of the FDFD model of the pipe-embedded building envelope in time domain, the time series of air temperatures in the chambers were transformed into Fourier series by using DFT. The 12-order Fourier series (i.e. 12 harmonics) are used to approximate the measured time series. The measured air temperature profile and its Fourier series expression approximation are plotted in Figure 10. The results show that the 12-order Fourier series can approximate the measured series of air temperatures well with the maximum relative error less than $1 \%$.

$<$ Figure 10 Fourier series approximation of the measured air temperatures $>$

\subsection{Results and Validation}

Surface temperatures and heat fluxes for these three surface, ie., the external and internal surfaces and the internal pipe surface of the test sample are used for comparison. The measured results by these experiments and calculated results by the FDFD model for these three cases with different supply water temperatures (i.e. $17.5^{\circ} \mathrm{C}, 19^{\circ} \mathrm{C}$ and $20^{\circ} \mathrm{C}$ ) and the same velocity $0.5 \mathrm{~m} / \mathrm{s}$ are presented in Figure 11-13. 
As shown in Figure 11, all the external surface heat fluxes of the test sample with different supply water temperatures predicted by the FDFD model agree well with the coincident measurement. The average relative errors with the supply water temperatures $17.5^{\circ} \mathrm{C}, 19^{\circ} \mathrm{C}$ and $20^{\circ} \mathrm{C}$ are about $6.5 \%, 4.1 \%$ and $6.1 \%$ respectively. The external surface heat flux profiles change rapidly in a day. Taking the case with the supply water temperature of $17.5^{\circ} \mathrm{C}$ for example, the maximum heat flux reaches up to $156.0 \mathrm{~W} / \mathrm{m}^{2}$ while the minimum only $13.8 \mathrm{~W} / \mathrm{m}^{2}$. The average external surface heat flux for this case is about $60 \mathrm{~W} / \mathrm{m}^{2}$. It also can be observed that the heat flux profiles for different supply water temperatures are quite similar both in variation trend and value.

$<$ Figure 11 External surface heat fluxes comparison with different supply water temperatures (a) $17.5^{\circ} \mathrm{C}$, (b) $19^{\circ} \mathrm{C}$, (c) $20^{\circ} \mathrm{C}>$

$<$ Figure 12 Internal pipe surface heat fluxes comparison with different supply water temperatures (a) $17.5^{\circ} \mathrm{C}$, (b) $19^{\circ} \mathrm{C}$, (c) $20^{\circ} \mathrm{C}>$

The internal pipe surface heat flow can be "measured" by multiplying the water flow rate with the temperature difference between the inlet and outlet. The internal pipe surface heat flux is defined as the pipe surface heat flow divided by the test sample area. Good agreement can be observed when comparing the predicted internal pipe surface heat fluxes by the FDFD model and the coincident measurement respectively as shown in Figure 12. The average relative errors between the prediction and the measurement corresponding to supply water temperatures $17.5^{\circ} \mathrm{C}, 19^{\circ} \mathrm{C}$ and $20^{\circ} \mathrm{C}$ are about $3.2 \%$, $3.8 \%$ and $4.4 \%$ respectively. The pipe surface heat flux changes relatively slowly in a day. Taking the case with the supply water temperature of $17.5^{\circ} \mathrm{C}$ for example, the maximum heat flux reaches $101.9 \mathrm{~W} / \mathrm{m}^{2}$ while the minimum $68.5 \mathrm{~W} / \mathrm{m}^{2}$. The average heat flux is kept at $81.7 \mathrm{~W} / \mathrm{m}^{2}$.

\section{$<$ Figure 13 Internal surface heat fluxes comparison with different supply water temperatures (a) $17.5^{\circ} \mathrm{C}$, (b) $19^{\circ} \mathrm{C}$, (c) $20^{\circ} \mathrm{C}>$}

Figure 13 shows the predicted internal surface heat flux by using the FDFD model and the measurement. The variation trend of the internal surface heat flux profiles of the test sample is quite similar with the measured ones although noticeable discrepancies may be observed. At most time, the predicted value by the FDFD model is lower than the 
measured data. The average relative errors for the supply water temperatures $17.5^{\circ} \mathrm{C}, 19$ ${ }^{\circ} \mathrm{C}$ and $20^{\circ} \mathrm{C}$ are $11.0 \%, 11.8 \%$ and $16.1 \%$ respectively. The main reason for this discrepancy may be that the signal of the internal surface heat flux is small and at the low range of the heat flow meter resulting in relatively large error. The internal surface heat flux is small, and a little absolute error caused by measurement device or system may lead to obvious discrepancy. The average internal surface heat fluxes coincident to the supply water temperatures $17.5^{\circ} \mathrm{C}, 19^{\circ} \mathrm{C}$ and $20^{\circ} \mathrm{C}$ are $25.5 \mathrm{~W} / \mathrm{m}^{2}, 21.3 \mathrm{~W} / \mathrm{m}^{2}$ and $17.5 \mathrm{~W} / \mathrm{m}^{2}$ respectively. This means that the pipe-embedded building envelope with cool water at about $19^{\circ} \mathrm{C}$ can effectively intercept the heat/coolth exchange between the ambient environment and the indoor space and provide considerable coolth for the indoor space at the same time.

The predicted external surface temperature profile by the FDFD model also agrees well with the measurement. The maximum individual absolute error between predicted and measured external surface temperatures is about $1.3^{\circ} \mathrm{C}$, and the relative errors less than $4.5 \%$. For the internal surface temperature, the maximum individual absolute error is about $0.8^{\circ} \mathrm{C}$, and the relative errors less than $3.5 \%$. The figures about the internal and external surface temperature are not presented for conciseness.

The inlet and outlet water temperatures and the water flow rate were measured. The internal pipe surface heat flow is actually calculated from the measured water flow rate, inlet and outlet temperatures. The test sample was subject to periodic thermal disturbances (period of 24h) from both test chambers respectively. The total heat transfers on the wall surfaces (external surface, internal surface and pipe surface) listed in Table 2 are the total surface heat transfers during a period (24h) after the heat transfer within the test sample reaches the semi-steady state. Noticeable discrepancies may be observed in predicting the transient values (i.e. surface heat flux) in some cases as shown in Figure 11-13. However, the total surface heat transfer in one period is predicted very well except the heat transfer of the internal surface of the test sample. For the total heat transfer on the external surface in one day, the relative errors corresponding to the supply water temperatures $17.5^{\circ} \mathrm{C}, 19^{\circ} \mathrm{C}$ and $20^{\circ} \mathrm{C}$ are respectively $1.53 \%, 2.04 \%$ and $1.19 \%$. For the total heat transfer on the pipe surface in one day, the relative errors corresponding to the supply water temperatures $17.5^{\circ} \mathrm{C}, 19^{\circ} \mathrm{C}$ and $20^{\circ} \mathrm{C}$ are $1.43 \%, 1.94 \%$ and $3.17 \%$ respectively. For the total heat transfer on the internal surface of the test sample in one 
day, the relative errors are a little large from $5.46 \%$ to $7.65 \%$. This is also due to that the signal of the internal surface heat flux is small and at the low range of the heat flow meter resulting in relatively large error. The reduction of the supply water temperature from 20 ${ }^{\circ} \mathrm{C}$ to $17.5^{\circ} \mathrm{C}$ results in $13.7 \%, 42.5 \%$ and $20.6 \%$ increase respectively in the external surface heat transfer, the internal surface heat transfer and internal pipe surface heat transfer. Therefore, the supply water temperature has a significant influence on the heat absorption of the internal surface of the test sample. Based on heat balance principle, the sum of the total heat transfers on the internal surface and external surface in one day is equal to the total heat transfer on the internal pipe surface in one day. The relative errors for considering the heat balance of the test sample from the measurements corresponding to the supply water temperatures $17.5^{\circ} \mathrm{C}, 19^{\circ} \mathrm{C}$ and $20^{\circ} \mathrm{C}$ are $4.49 \%, 1.47 \%$ and $1.13 \%$ respectively. The calculated results by the FDFD model corresponding to different supply water temperatures also comply with the heat balance principle with the maximum error $0.22 \%$. The observed discrepancy in the heat balance analysis of the test sample based on the measurements may be mainly caused by the error of the measurement devices.

$<$ Table 2 Total heat transfers on these three surfaces in one day $>$

The comparison above shows that the predicted thermal performance by using the FDFD model and measured thermal performance of the test sample (i.e., the pipeembedded building envelope sample) are in a good agreement with each other. It indicates that the FDFD model may predict the real thermal responses of the pipe-embedded building envelope accurately. In addition, FDFD model needs much less time in solving the periodic heat transfer problem than the conventional time-domain numerical models such as Finite Volume Model (FVM), Finite Element Model (FEM) etc. Generally, for the same common configured desktop computer with Inter core i7-3770 of 8 core processor, frequency of $3.4 \mathrm{GHz}$, and memory of 16G, FDFD model only costs less than 1 minute while the FVM model may cost about 2 hours when their meshing numbers are the same.

\section{Conclusion}

The Frequency-Domain Finite-Difference (FDFD) model of the pipe-embedded building envelope is validated in time domain against the experimental measurements from an experiment test rig. For validating the FDFD model, the boundary conditions including air temperature and water temperature time series are transformed as complex 
Fourier series by using DFT and applied into the FDFD model as inputs for calculation. The frequency thermal responses calculated by the FDFD model are transformed into time series by IDFT. 12-order Fourier series can be used to approximate the air temperature series well.

The experiment was conducted efficiently in predefined conditions, and different supply water temperatures were used for test. The results show that the FDFD model can predict the real thermal performance of the pipe-embedded building envelope accurately. The average relative errors between the measurement and the prediction by the FDFD model for the external surface heat flux and the internal pipe surface heat flux of the pipe-embedded building envelope sample are less than $6.5 \%$ and $4.4 \%$ respectively. The average relative error for the internal surface heat flux of the sample is a little large of $16.1 \%$. The main reason may be that the signal of the internal surface heat flux is small and at the low range of the heat flow meter resulting in relatively large error. The predicted external and internal surface temperature profiles of the sample by the FDFD model also agree well with the measurements. The maximum differences between prediction and measurement for the external surface and internal surface temperatures are about $1.3^{\circ} \mathrm{C}$ and $0.8^{\circ} \mathrm{C}$, respectively. Both the predicted and measured total heat transfers on different surfaces in one day also agree well. The results further show that validation of FDFD model in time by Fourier series analysis is intuitional and efficient.

Good heat intercept effect and space conditioning potential of the pipe-embedded building envelope are also observed from the measurements. When the supply water temperature is $17.5^{\circ} \mathrm{C}$, the heat absorption of the internal surface of the pipe-embedded building envelope may reach up $25 \mathrm{~W} / \mathrm{m}^{2}$. This value will be further increased by changing the position of the embedded pipe more close to the internal surface of the pipe-embedded building envelope, which will be studied in the future work.

\section{Acknowledgements}

This work presented in this paper is financially supported by a grant (No. 51178201) of National Science Foundation of China and supported by the research fund of "Program for New Century Excellent Talents in University" (No. 2011CDB292) as well as a grant (No. 20120142110078). 


\section{References}

[1] Xu Xinhua, Wang Shengwei, Wang Jinbo, et al., Active pipe-embedded structures in buildings for utilizing low-grade energy sources: A review, Energy and Buildings, 42 (10) ( 2010) 567-1581.

[2] Wang Lin-Shu, Ma Peizheng, Hu Enyuan, et al., A study of building envelope and thermal mass requirements for achieving thermal autonomy in an office building, Energy and Buildings, 78 (2014) 79-88.

[3] Favre B., Peuportier B., Application of dynamic programming to study load shifting in buildings, Energy and Buildings, 82 (2014) 57-64.

[4] Lehmann B., Dorer V., Koschenz M., Application range of thermally activated building systems tabs, Energy and Buildings, 39 (2007) 593-598.

[5] Saelens D., Parys W. Baetens R., Energy and comfort performance of thermally activated building systems including occupant behavior, Building and Environment, 46 (2011) 835-848.

[6] Liu Kuixing, Tian Zhe, Zhang Cheng, et al., Establishment and validation of modified star-type RC-network model for concrete core cooling slab, Energy and Buildings 43 (2011) 2378-2384.

[7] Dréau J.L. Heiselberg P., Sensitivity analysis of the thermal performance of radiant and convective terminals for cooling buildings, Energy and Buildings, 82 (2014) 482-491.

[8] Zhang Z., Pate M.B., A semi-analytical formulation for heat transfer from structures with embedded tubes, in: The 24th National Heat Transfer Conference, ASME-HTD, vol. 78, Pittsburgh, Pennsylvania, August 9-12, 1987, pp. 17-25.

[9] Antonopoulos K. A., Analytical and numerical heat transfer in cooling panels, Heat and Transfer, 35 (1992) 2777-2782.

[10] Chen Y., Athienitis A. K., Galal K. E., Frequency domain and finite difference modeling of ventilated concrete slabs and comparison with field measurements: Part 1, modeling methodology, International Journal of Heat and Mass Transfer 66 (2013) 948-956.

[11] Tian Zhe, Duan Baodong, Niu Xiaolei, et al., Establishment and experimental validation of a dynamic heat transfer model for concrete radiant cooling slab based on reaction coefficient method, Energy and Buildings, 82 (2014) 330-340.

[12] Zhang Z., Pate M.B., A numerical study of heat transfer in a hydronic radiant ceiling panel, ASME-HTD Winter Annual Meeting, vol. 62, Anaheim, CA, 
December 7-12 (1986), pp. 31-37.

[13] Zhang Z., Pate M.B., An experimental study of the transient response of a radiant panel ceiling and enclosure, ASHRAE Transactions, 92 (2A) (1986), pp. 85-94.

[14] Ho S.Y., Hayes R.E., Wood R.K., Simulation of the dynamic behaviour of a hydronic floor heating system, Heat Recovery Systems and CHP 15(6) (1995) 505-519.

[15] Antonopoulos K.A., Tzivanidis C., Numerical solution of unsteady three-dimensional heat transfer during space cooling using ceiling-embedded piping, Energy, 22 (1) (1997), pp. 59-67.

[16] Jin Xing, Zhang Xiaosong, Luo Yajun. et al., Numerical simulation of radiant floor cooling system: The effects of thermal: resistance of pipe and water velocity on the performance, Building and Environment, 45 (2010) 2545-2552.

[17] Carli M. D., Scarpa M., Tomasi R., et al., DIGITHON: A numerical model for the thermal balance of rooms equipped with radiant systems, Building and Environment, 57 (2012) 126-144.

[18] Wang Dengjia, Liu Yanfeng, Wang Yingying, et al., Numerical and experimental analysis of floor heat storage and release during an intermittent in-slab floor heating process, Applied Thermal Engineering, 62 (2014) 398-406.

[19] Chabory A., de Hon B.P., Schilders W.H.A., et al., Fast transform based preconditioners for 2D finite-difference frequency-domain-Waveguides and periodic structures, Journal of Computational Physics, 227 (2008) 7755-7767.

[20] Melazzi D., Curreli D., Manente M., et al., SPIREs: A Finite-Difference Frequency-Domain electromagnetic solver for inhomogeneous magnetized plasma cylinders, Computer Physics Communications, 183 (2012) 1182-1191.

[21] Xie Junlong, Zhu Qiuyuan , Xu Xinhua, An active pipe-embedded building envelope for utilizing low-grade energy sources, Journal of Central South University, June 19 (2012) 1663-1667.

[22] Zhu Qiuyuan, Xu Xinhua, Wang Jinbo, et al., Development of dynamic simplified thermal models of active pipe-embedded building envelopes using genetic algorithm, International Journal of Thermal Sciences, 76 (2014) 258-272.

[23] Kreyszig E., Advanced Engineering Mathematics, tenth ed., John Wiley \& Sons, 2011.

[24] Weber T., Energy performance of buildings/methodologies for experimental verification, Doctoral Dissertation, Division of Building Technology, Department of 
Civil and Architectural Engineering, KTH-Royal Institute of Technology, Stockholm, Sweden, 2004.

[25] Saad Y. , Schultz M.H., GMRES: a generalized minimal residual algorithm for solving nonsymmetrical linear systems, SIAM J. Sci. Stat. Comput. 7 (1986) 856-869.

[26] Oppenheim A.V., Willsky A.S., Hamid S., Signal \& System (Second Edition).Prentice Hall, New Jersey, 1996. 


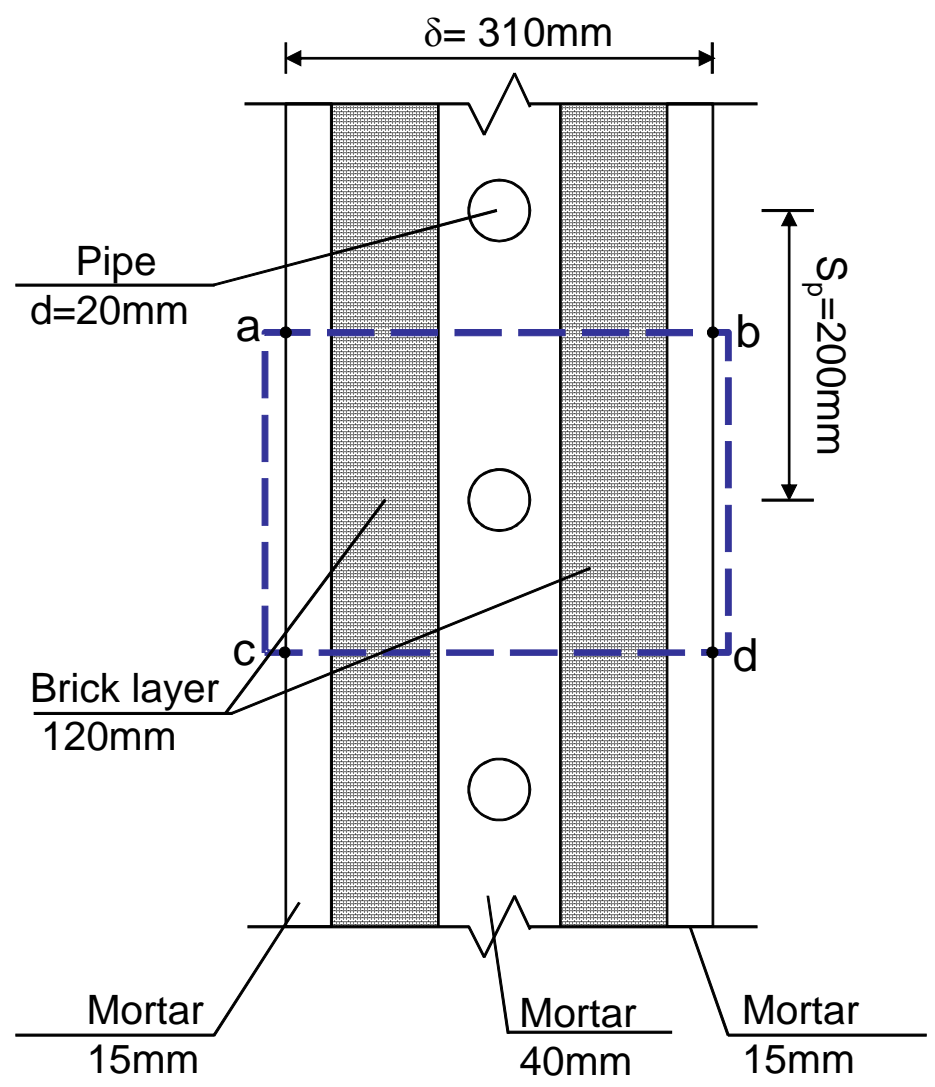

Figure 1 Schematic of the cross section of the active pipe-embedded building envelope 


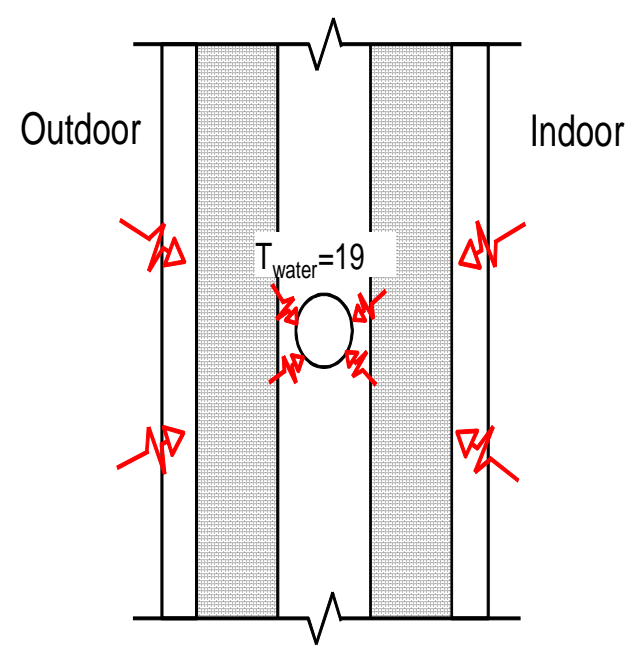

(a)

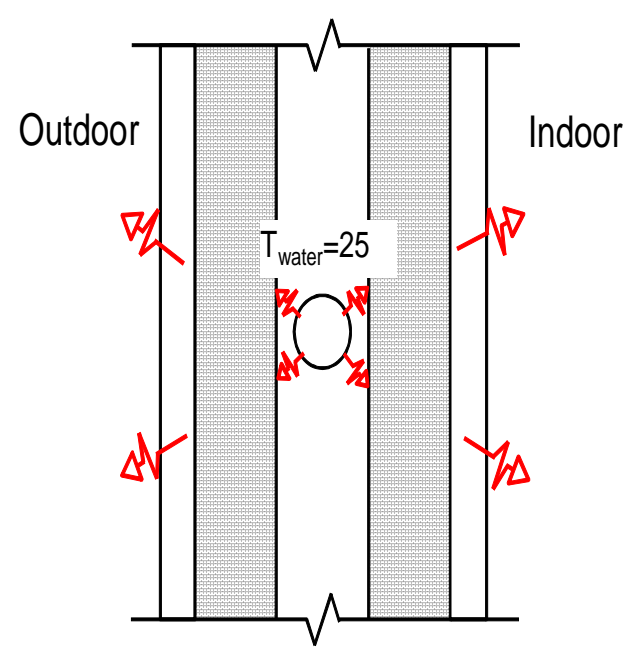

(b)

Figure 2 Typical operations of the active pipe-embedded building envelope, (a) cooling condition, (b) heating condition 


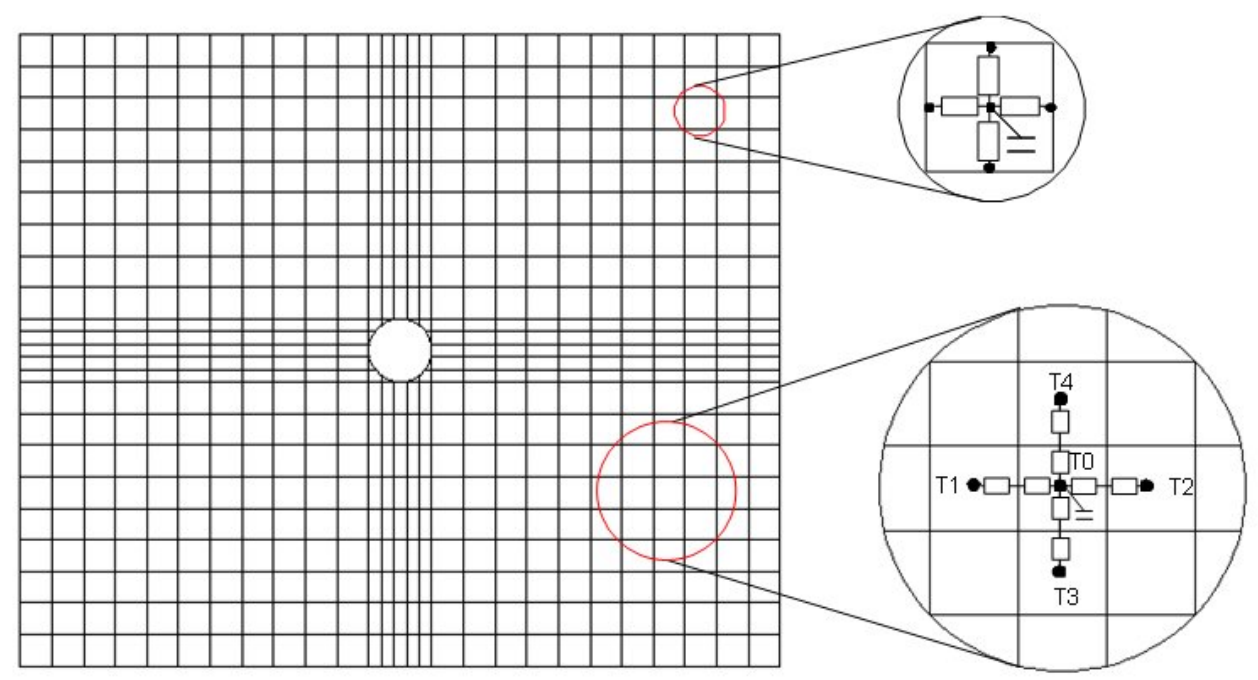

Figure 3 Discrete grid model of the active-embedded building envelope 


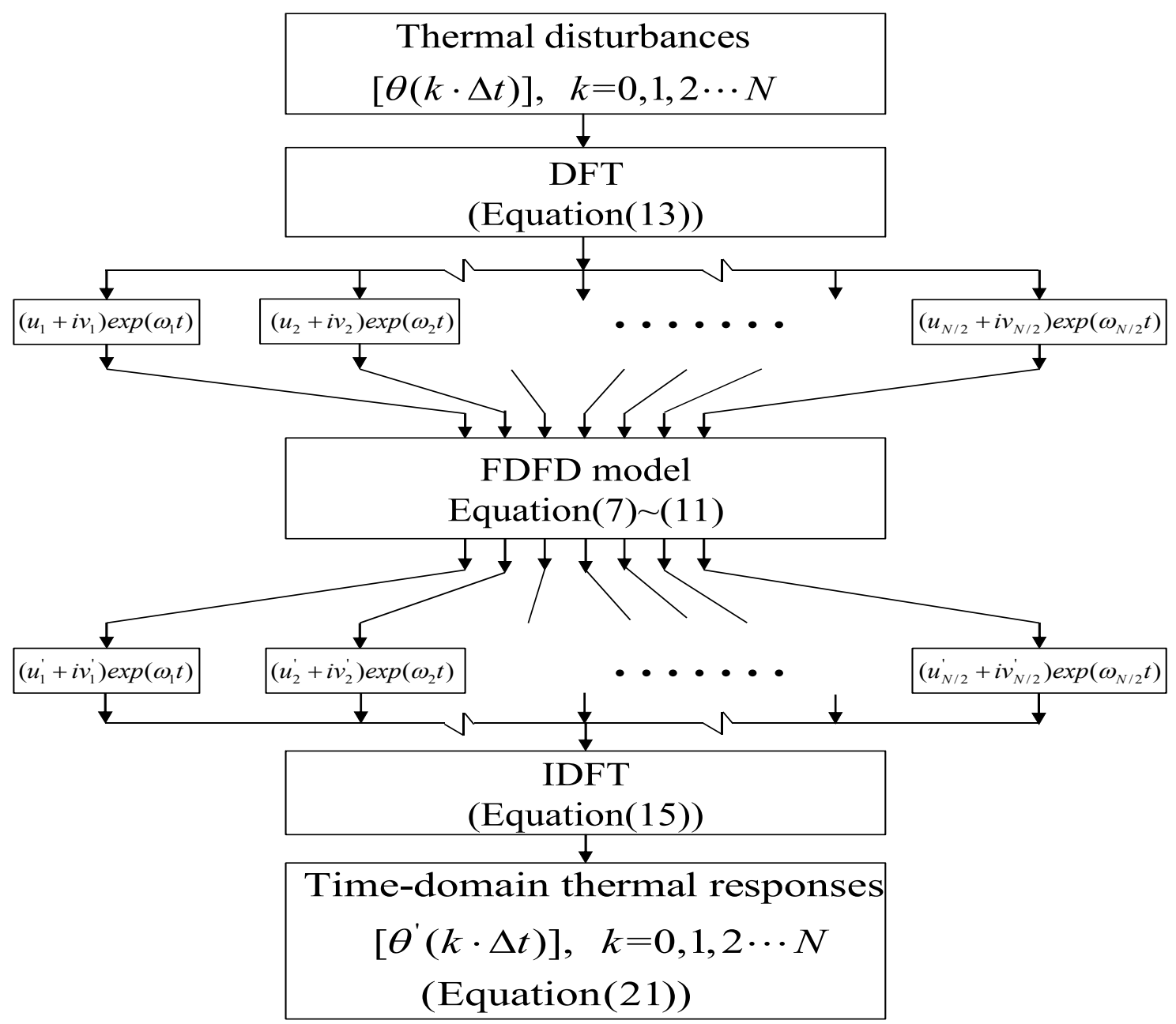

Figure 4 The process of solving the time-domain thermal responses of FDFD model 


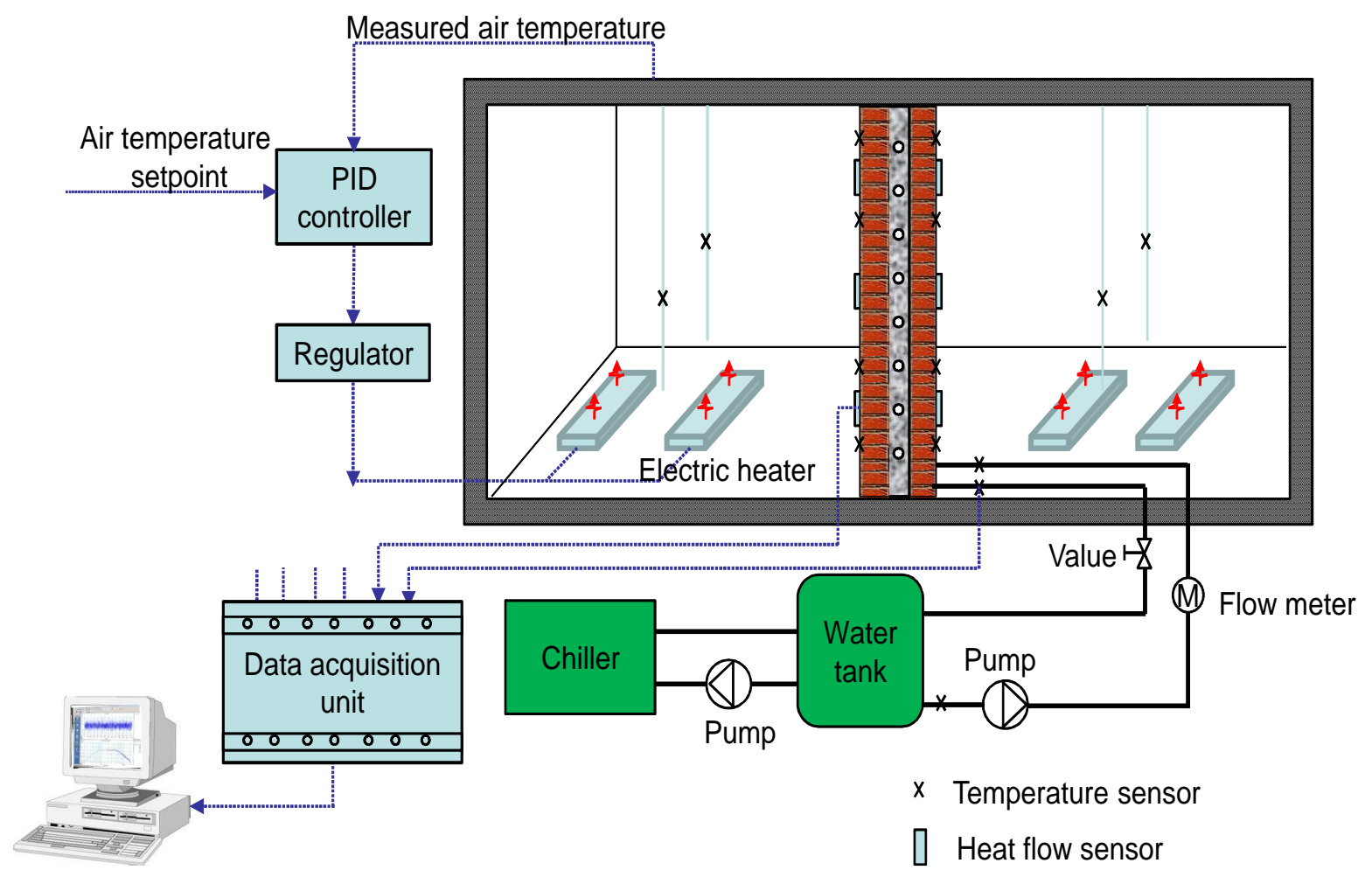

Figure 5 Schematic diagram of the experiment test rig 


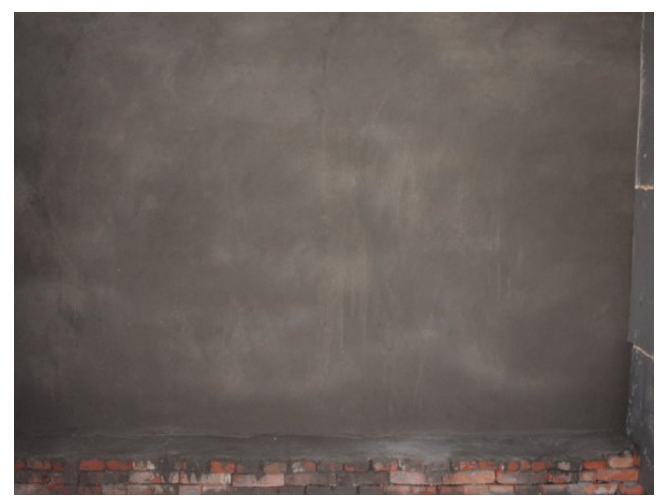

(a)

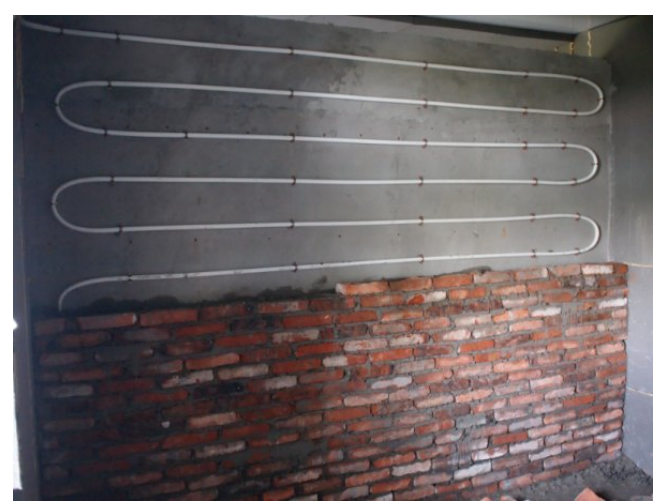

(c)

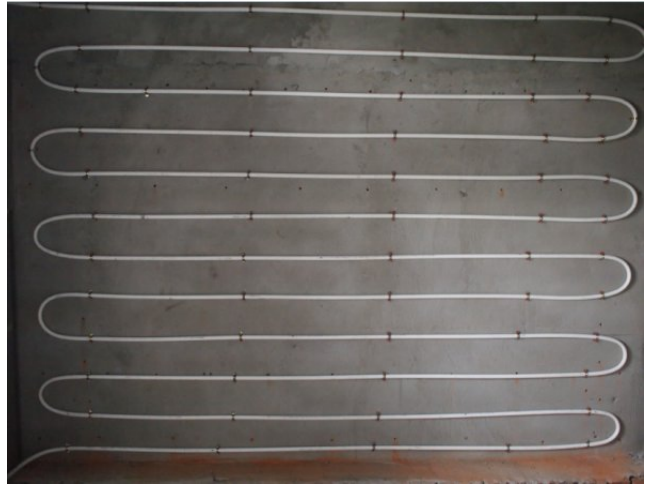

(b)

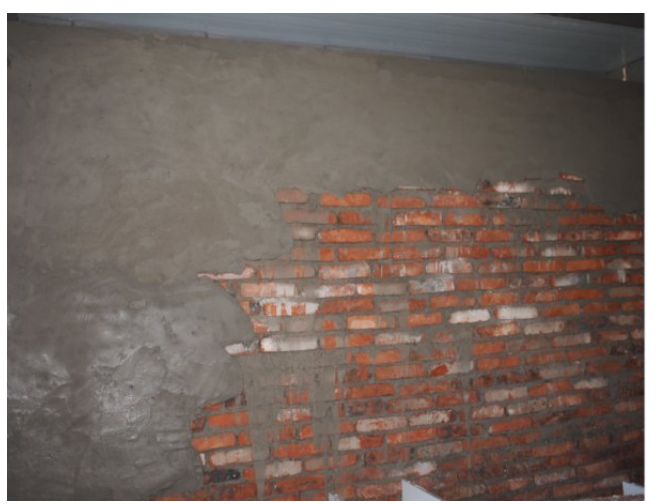

(d)

Figure 6 Construction process of the pipe-embedded building wall 


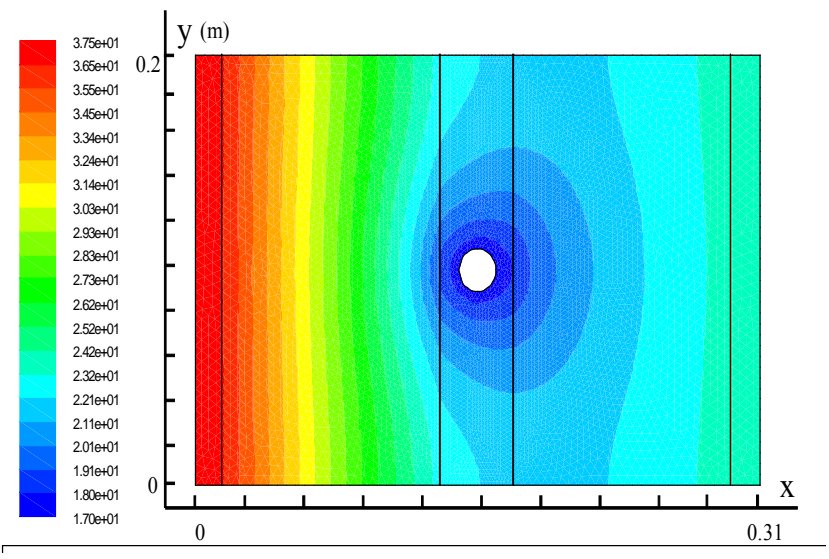

(a)

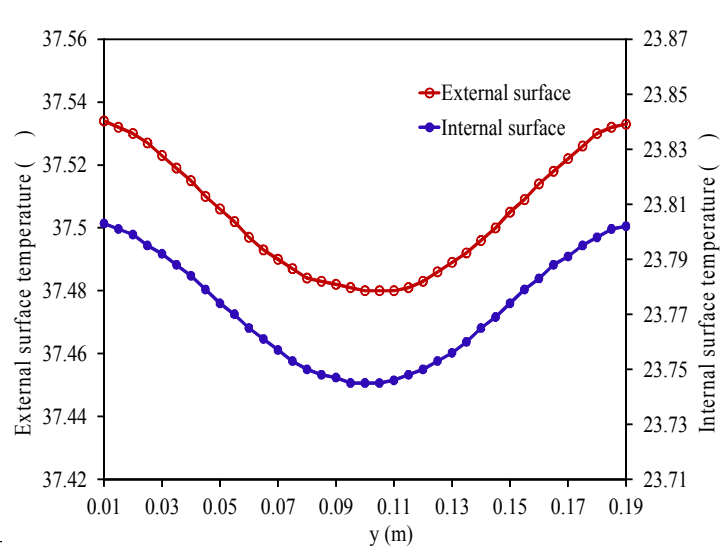

(b)

Figure 7 The temperature distribution of the pipe-embedded building envelope. (a) two-dimensional temperature distribution on the cross section, (b) one-dimensional temperature distribution on the external surface and internal surface 


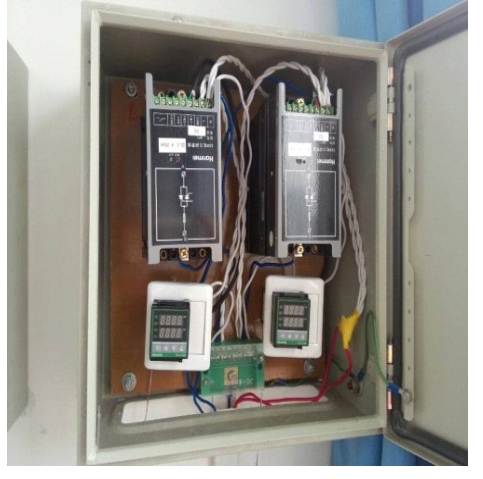

(a)

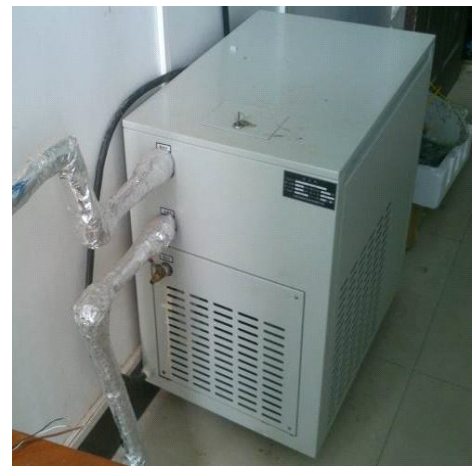

(b)

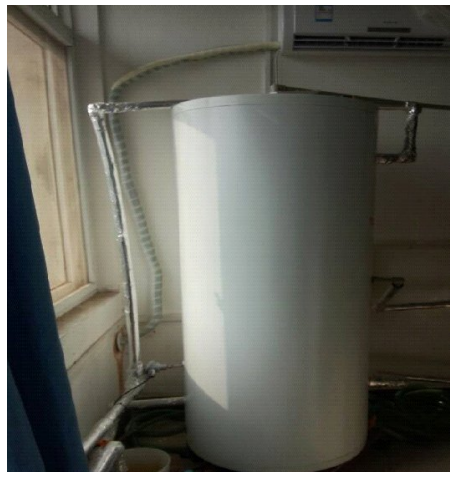

(c)

Figure 8 Some experimental devices (a) PID controller, (b) Chiller, (c) Water Tank 


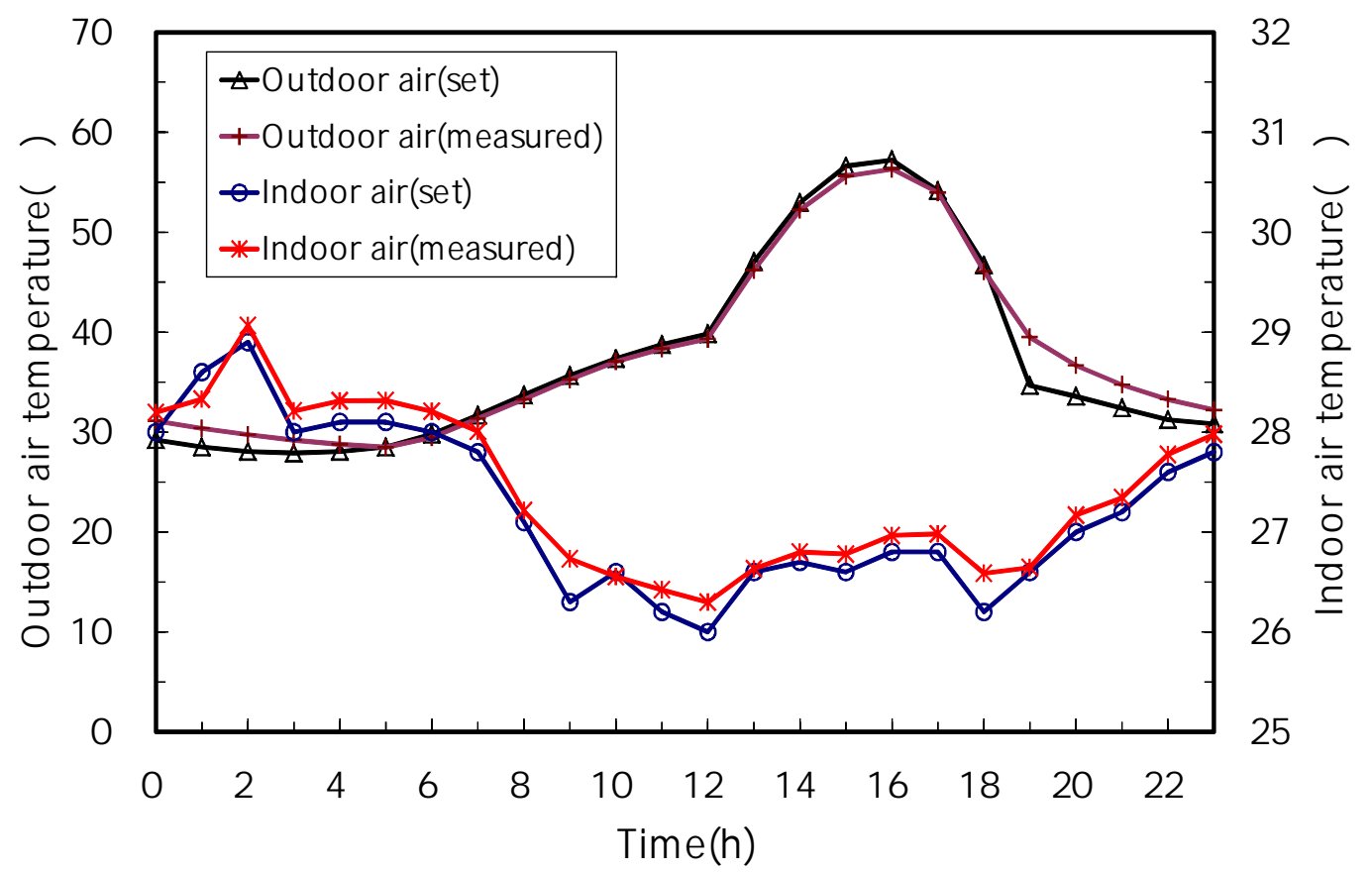

Figure 9 The predefined and measured air temperature profiles in both chambers 


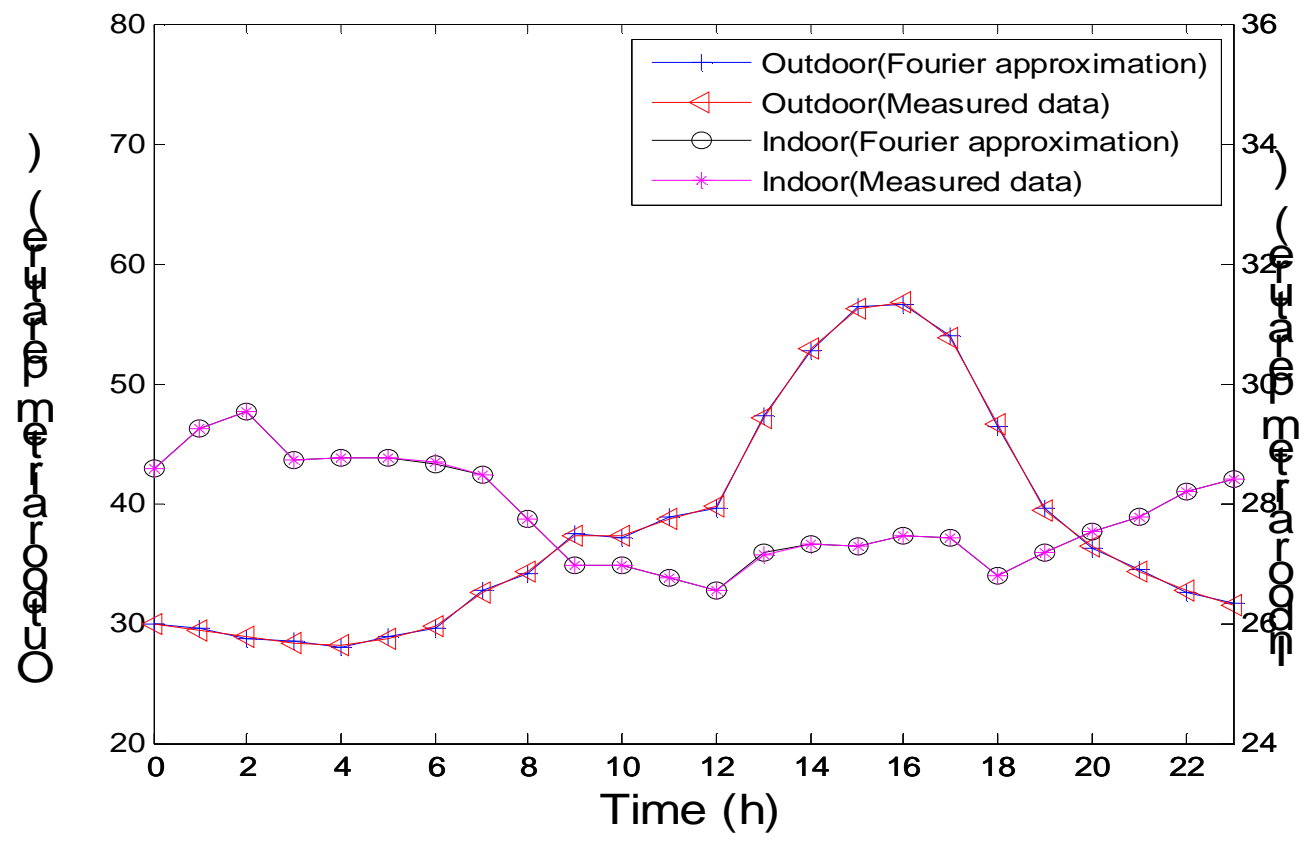

Figure 10 Fourier series approximation of the measured air temperatures 


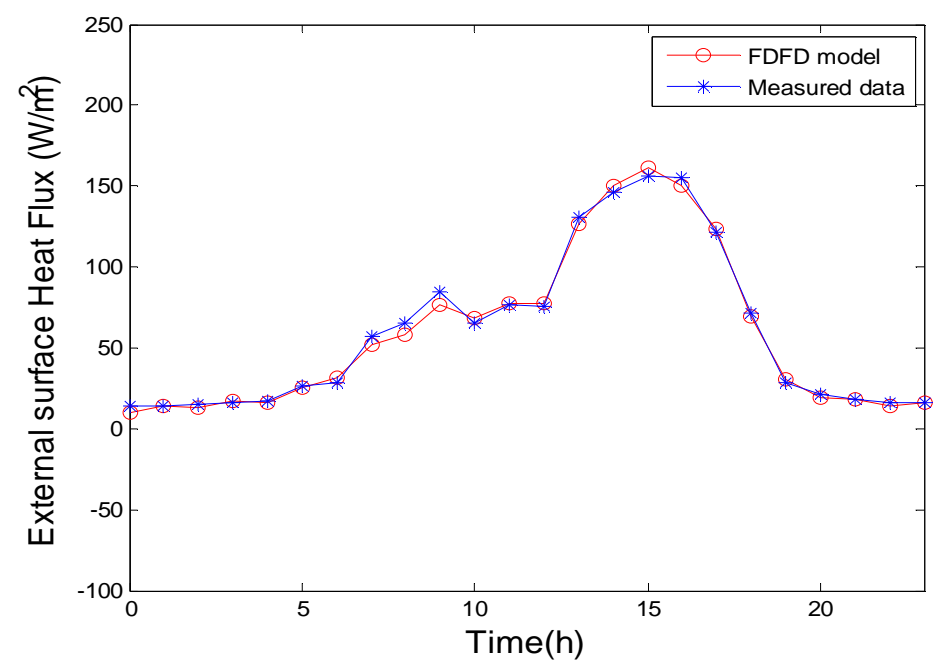

(a)

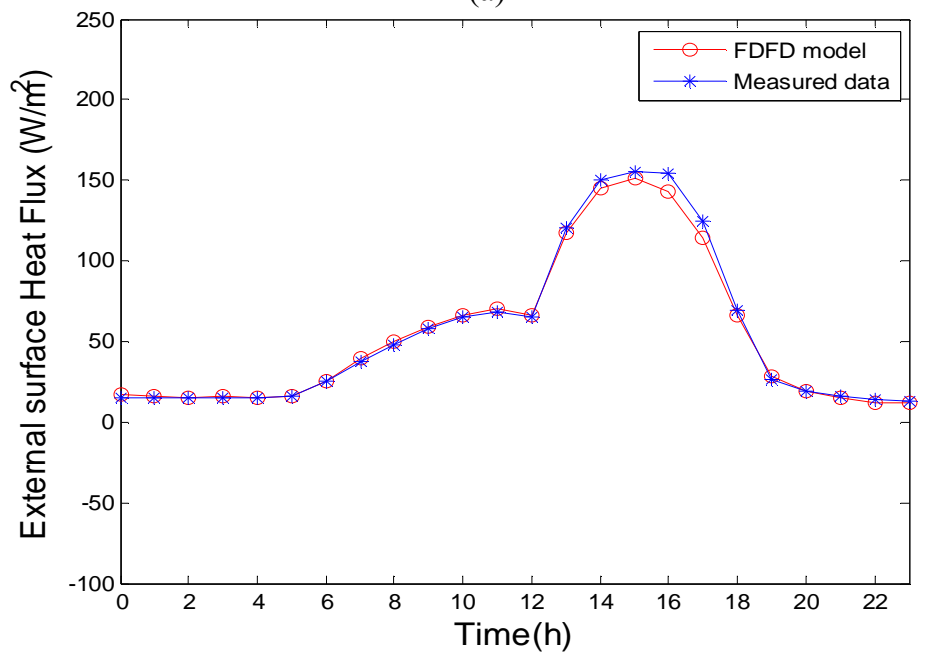

(b)

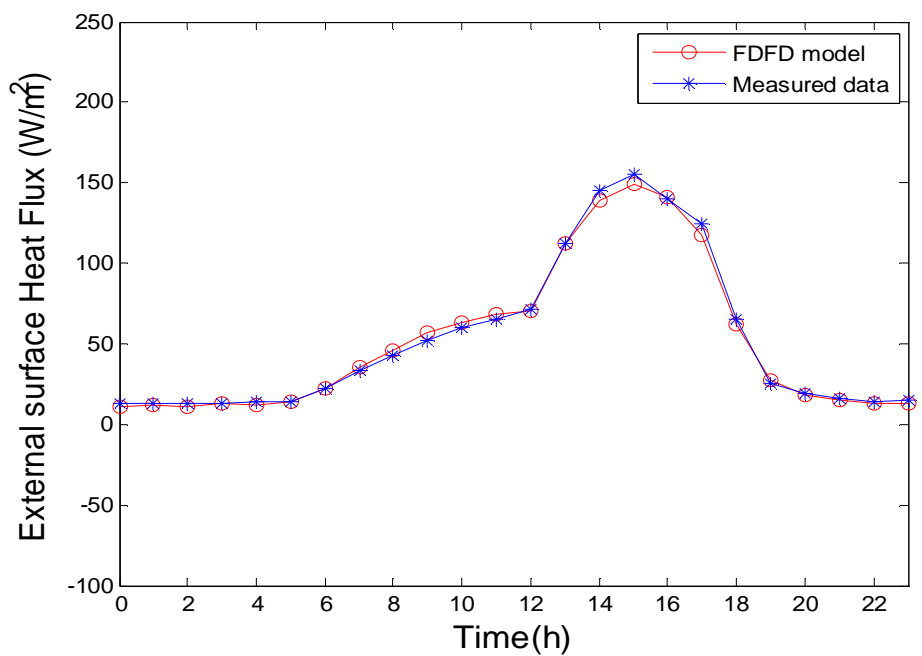

(c)

Figure 11 External surface heat fluxes comparison with different supply water 
temperatures

(a) $17.5^{\circ} \mathrm{C}$, (b) $19^{\circ} \mathrm{C}$, (c) $20^{\circ} \mathrm{C}$ 


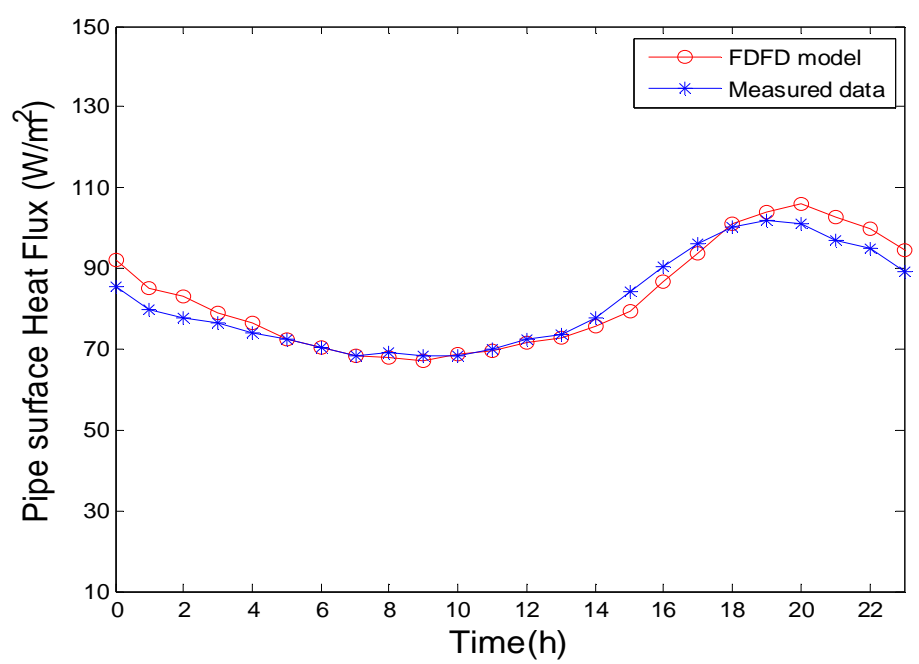

(a)

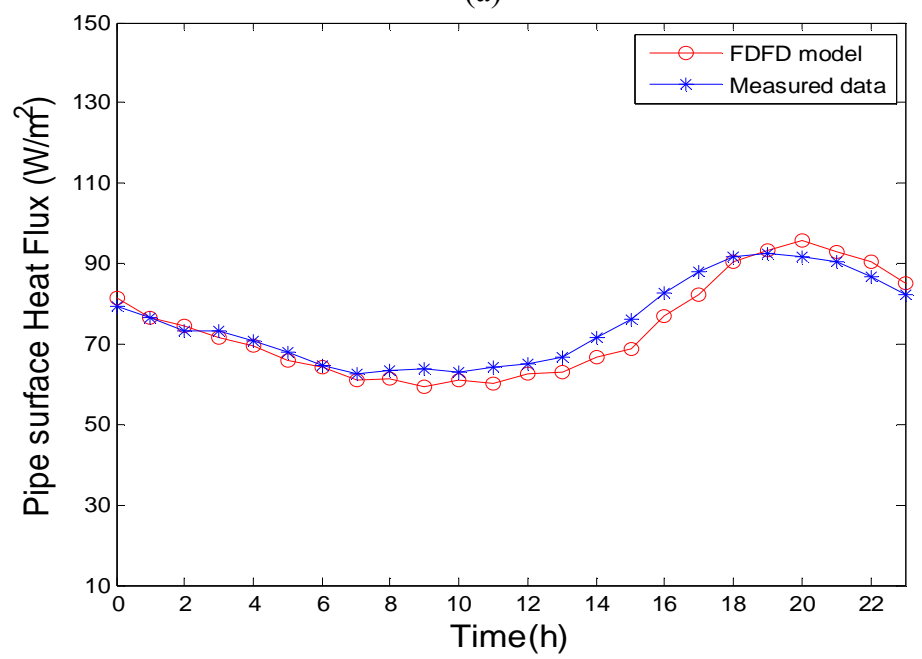

(b)

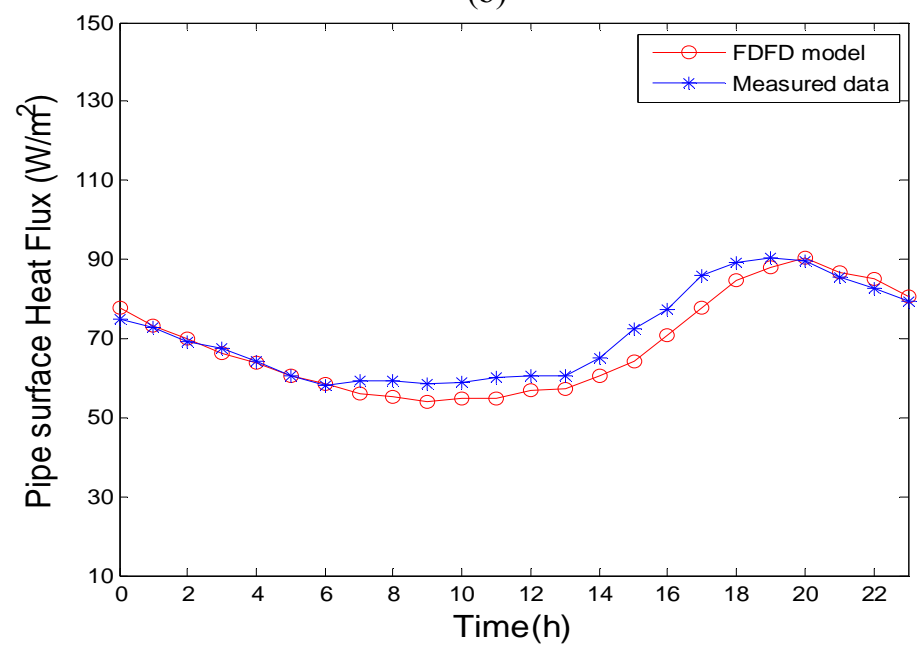

(c)

Figure 12 Internal pipe surface heat fluxes comparison with different supply water 
temperatures (a) $17.5^{\circ} \mathrm{C}$, (b) $19^{\circ} \mathrm{C}$, (c) $20^{\circ} \mathrm{C}$ 


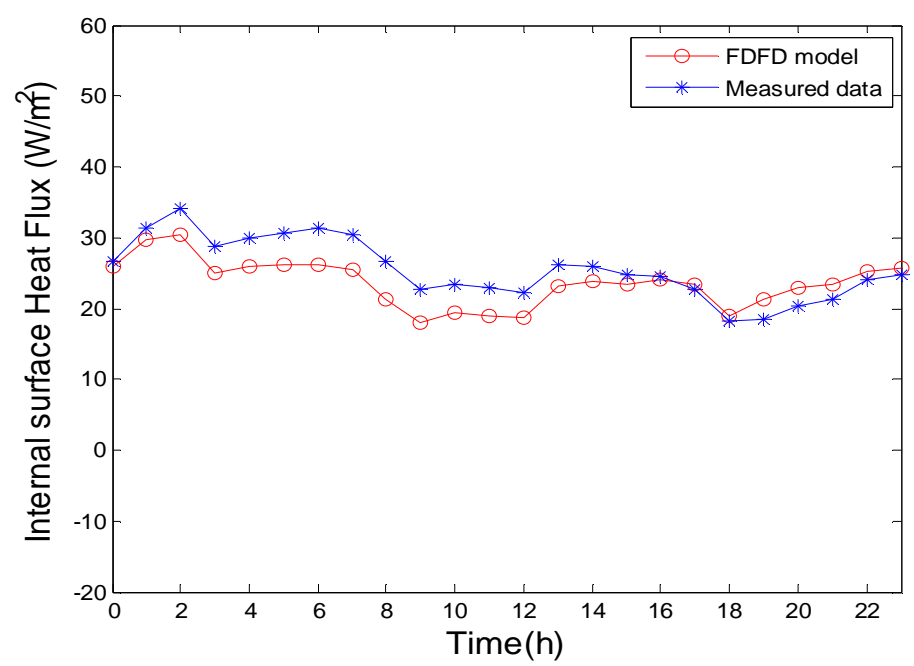

(a)

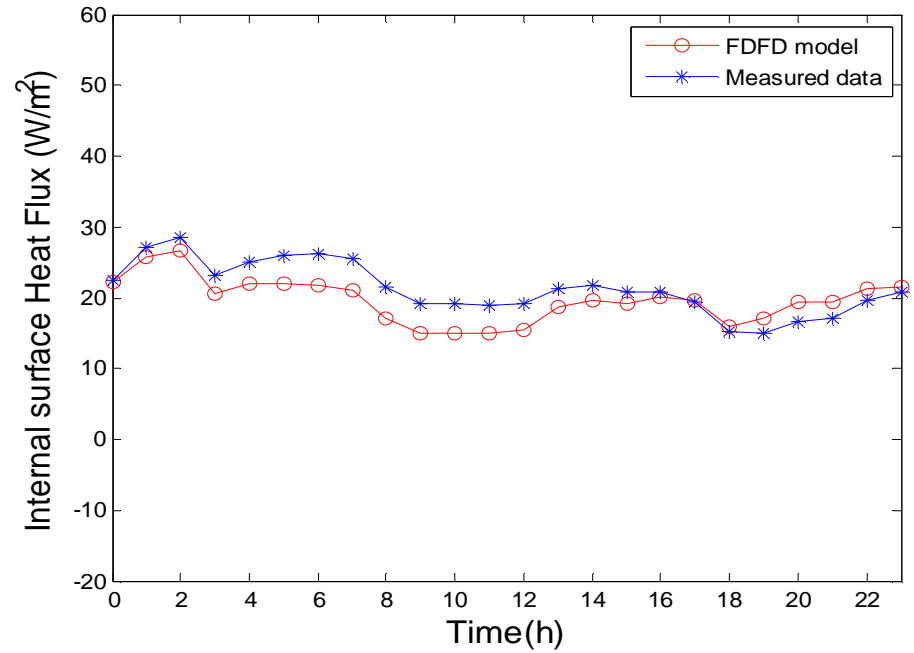

(b)

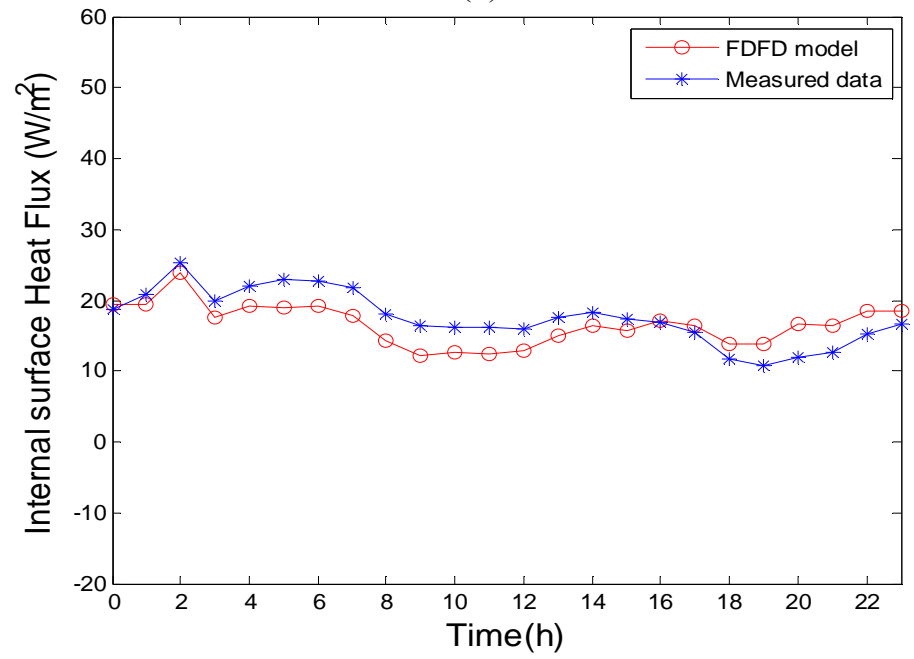

(c)

Figure 13 Internal surface heat fluxes comparison with different supply water temperatures 
(a) $17.5^{\circ} \mathrm{C}$, (b) $19^{\circ} \mathrm{C}$, (c) $20^{\circ} \mathrm{C}$ 


\section{Figure Captions}

Figure 1 Schematic of the cross section of the active pipe-embedded building envelope

Figure 2 Typical operations of the active pipe-embedded building envelope, (a) cooling condition, (b) heating condition

Figure 3 Discrete grid model of the active-embedded building envelope

Figure 4 The process of solving the time-domain thermal responses of FDFD model

Figure 5 Schematic diagram of the experiment test rig

Figure 6 Construction process of the pipe-embedded building wall

Figure 7 The temperature distribution of the pipe-embedded building envelope. (a) two-dimensional temperature distribution on the cross section, (b) one-dimensional temperature distribution on the external surface and internal surface

Figure 8 Some experimental devices (a) PID controller, (b) Chiller, (c) Water Tank

Figure 9 The predefined and measured air temperature profiles in both chambers

Figure 10 Fourier series approximation of the measured air temperatures

Figure 11 External surface heat fluxes comparison with different supply water temperatures (a) $17.5^{\circ} \mathrm{C}$, (b) $19^{\circ} \mathrm{C}$, (c) $20^{\circ} \mathrm{C}$

Figure 12 Internal pipe surface heat fluxes comparison with different supply water temperatures (a) $17.5^{\circ} \mathrm{C}$, (b) $19^{\circ} \mathrm{C}$, (c) $20^{\circ} \mathrm{C}$

Figure 13 Internal surface heat fluxes comparison with different supply water temperatures (a) $17.5^{\circ} \mathrm{C}$, (b) $19^{\circ} \mathrm{C}$, (c) $20^{\circ} \mathrm{C}$ 
Table 1 Thermal properties of the brick and mortar in the test sample

\begin{tabular}{ccccc}
\hline & $\begin{array}{c}\text { Thickness } \\
\delta(\mathrm{mm})\end{array}$ & $\begin{array}{c}\text { Density } \\
\rho\left(\mathrm{kg} / \mathrm{m}^{3}\right)\end{array}$ & $\begin{array}{c}\text { Thermal } \\
\text { conductivity } \\
\lambda(\mathrm{W} / \mathrm{m} \cdot \mathrm{K})\end{array}$ & $\begin{array}{c}\text { Specific heat } \\
\text { capacity } c \\
(\mathrm{~J} / \mathrm{kg} \cdot \mathrm{K})\end{array}$ \\
\hline Brick layer & 120 & 1790 & 0.76 & 1025 \\
Pipe-embedded mortar layer & 40 & 2234 & 1.71 & 1160 \\
External surface mortar layer & 15 & 2234 & 1.71 & 1160 \\
Internal surface mortar layer & 15 & 2234 & 1.71 & 1160 \\
\hline
\end{tabular}

Table 2 Total heat transfers on these three surfaces in one day

\begin{tabular}{|c|c|c|c|c|c|c|}
\hline \multirow{2}{*}{$\begin{array}{c}\text { Supply water } \\
\text { temperature } \\
\left({ }^{\circ} \mathrm{C}\right)\end{array}$} & \multicolumn{6}{|c|}{ Total surface heat transfer in one day (kWh) } \\
\hline & & $\begin{array}{c}\text { External } \\
\text { surface }\end{array}$ & $\begin{array}{l}\text { Internal } \\
\text { surface }\end{array}$ & Sum* & Pipe surface & Error $^{\#}(\%)$ \\
\hline & Experiment & 10.967 & 4.661 & 15.628 & 14.927 & 4.49 \\
\hline 17.5 & $\begin{array}{l}\text { FDFD model } \\
\text { Error }(\%)\end{array}$ & $\begin{array}{l}10.799 \\
1.53\end{array}$ & $\begin{array}{l}4.318 \\
7.35\end{array}$ & $\begin{array}{c}15.117 \\
-\end{array}$ & $\begin{array}{c}15.141 \\
1.43\end{array}$ & $\begin{array}{c}0.16 \\
-\end{array}$ \\
\hline 19 & $\begin{array}{l}\text { Experiment } \\
\text { FDFD model } \\
\text { Error }(\%)\end{array}$ & $\begin{array}{c}10.091 \\
9.886 \\
2.04\end{array}$ & $\begin{array}{c}3.884 \\
3.587 \\
7.65\end{array}$ & $\begin{array}{c}13.975 \\
13.473 \\
-\end{array}$ & $\begin{array}{c}13.770 \\
13.503 \\
1.94\end{array}$ & $\begin{array}{l}1.47 \\
0.22 \\
-\end{array}$ \\
\hline 20 & $\begin{array}{l}\text { Experiment } \\
\text { FDFD model } \\
\text { Error }(\%)\end{array}$ & $\begin{array}{c}9.611 \\
9.497 \\
1.19 \\
\end{array}$ & $\begin{array}{c}3.206 \\
3.031 \\
5.46 \\
\end{array}$ & $\begin{array}{c}12.817 \\
12.528 \\
- \\
\end{array}$ & $\begin{array}{c}12.962 \\
12.551 \\
3.17 \\
\end{array}$ & $\begin{array}{c}1.13 \\
0.18 \\
- \\
\end{array}$ \\
\hline
\end{tabular}

(* refers to the sum of the total heat transfer on the internal surface and external surface in one day. ${ }^{\text {\# }}$ refers to the relative error between the sum of the total heat transfers on internal surface and external surface in one day and the total heat transfer on the internal pipe surface in one day) 